Article

\title{
Monitoring Vineyard Canopy Management Operations Using UAV-Acquired Photogrammetric Point Clouds
}

\author{
Francisca López-Granados ${ }^{1, *}$, Jorge Torres-Sánchez ${ }^{1}{ }^{(0)}$, Francisco M. Jiménez-Brenes ${ }^{1}(\mathbb{D}$, \\ Oihane Oneka $^{2}$, Diana Marín ${ }^{2}$, Maite Loidi ${ }^{2}$, Ana I. de Castro 1,3 (D) and L. G. Santesteban ${ }^{2}$ (D) \\ 1 Grupo Imaping, Instituto de Agricultura Sostenible-CSIC, Avda. Menéndez Pidal, s/n, 14004 Córdoba, Spain; \\ jtorres@ias.csic.es (J.T.-S.); fmjimenez@ias.csic.es (F.M.J.-B.); o92camea@uco.es (A.I.d.C.) \\ 2 Universidad Pública de Navarra, Dpto. Agronomía, Biotecnología y Alimentación, Edificio Los Olivos, \\ 31006 Pamplona, Spain; oihane.oneka@unavarra.es (O.O.); diana.marin@unavarra.es (D.M.); \\ maite.loidi@unavarra.es (M.L.); gonzaga.santesteban@unavarra.es (L.G.S.) \\ 3 Departamento de Ingeniería Gráfica y Geomática, Universidad de Córdoba, Campus de Rabanales, Crta. IV, \\ km. 396, E-14071 Córdoba, Spain \\ * Correspondence: flgranados@ias.csic.es
}

Received: 15 June 2020; Accepted: 15 July 2020; Published: 20 July 2020

\begin{abstract}
Canopy management operations, such as shoot thinning, leaf removal, and shoot trimming, are among the most relevant agricultural practices in viticulture. However, the supervision of these tasks demands a visual inspection of the whole vineyard, which is time-consuming and laborious. The application of photogrammetric techniques to images acquired with an Unmanned Aerial Vehicle (UAV) has proved to be an efficient way to measure woody crops canopy. Consequently, the objective of this work was to determine whether the use of UAV photogrammetry allows the detection of canopy management operations. A UAV equipped with an RGB digital camera was used to acquire images with high overlap over different canopy management experiments in four vineyards with the aim of characterizing vine dimensions before and after shoot thinning, leaf removal, and shoot trimming operations. The images were processed to generate photogrammetric point clouds of every vine that were analyzed using a fully automated object-based image analysis algorithm. Two approaches were tested in the analysis of the UAV derived data: (1) to determine whether the comparison of the vine dimensions before and after the treatments allowed the detection of the canopy management operations; and (2) to study the vine dimensions after the operations and assess the possibility of detecting these operations using only the data from the flight after them. The first approach successfully detected the canopy management. Regarding the second approach, significant differences in the vine dimensions after the treatments were detected in all the experiments, and the vines under the shoot trimming treatment could be easily and accurately detected based on a fixed threshold.
\end{abstract}

Keywords: shoot thinning; leaf removal; shoot trimming; remote sensing; change detection; 3D mapping; OBIA

\section{Introduction}

Vineyard management includes a wide variety of operations such as canopy management, phytochemical applications, pruning, soil management, irrigation and fertilization scheduling, and application of soil amendments. Canopy management comprises some of the most relevant practices in viticulture being performed at least once a year in most vineyards around the world. Among canopy management practices, the most relevant are: 
- Shoot thinning: this consists of the selective removal of shoots in spring and, somehow, complements the winter pruning. At this operation, shoots are removed or not depending on their position in the spur or cane, and on their fruitfulness. The objectives of this task are yield adjustment and bunch microclimate improvement. This operation is necessarily done by hand operators.

- Shoot trimming: this is the cutting of the shoot upper part, and it is carried out during the summer. Its main goals are to ease machinery traffic along the lanes, to increase bunch exposure to sunlight and to phytochemical treatments and, sometimes, to improve fruit set. This operation is mostly performed with specific farming implements.

- Leaf removal: this is the detachment of leaves from the fruit zone, and can be executed at any time between fruit set and harvest. The main goal of this operation is to increase bunch exposition to sunlight and phytochemical treatments, as well as improving aeration of the bunch area to diminish fungal pathogen incidence. This practice, together with shoot trimming, is being studied as a technique to delay ripeness and compensate the consequences of global warming on fruit sugar concentration [1-3].

The accomplishment of the canopy management operations is sometimes carried out by temporary workers or external contractors, and it is important for field managers to be sure that they are performed in a timely and proper way. However, the supervision of these tasks is currently based on time-consuming field inspections, only feasible in a small fraction of the total acreage. Alternatives to the field inspections aimed at verifying the proper completion of these tasks have arisen to overcome this problem in the last years. For example, accurate three-dimensional (3D) modeling and characterization of crop canopies have been achieved using different technologies, such as aerial photogrammetry by means of unmanned aerial vehicles (UAVs) acquired images [4,5], and also LIDAR (light detection and ranging) [6,7], ultrasonic sensors [8,9], or depth cameras [10,11] for mapping 3D structure in different crops. In an economic study, the use of photogrammetric techniques applied in UAV-images has been reported as the most efficient method to geometrically and accurately characterize a vineyard when compared to LIDAR and depth-camera sensors on board on-ground vehicles [12].

UAV photogrammetry can generate two different outputs for 3D measurement of crops: digital surface models (DSM) and point clouds. The main difference between them is that whereas DSMs only store one height value for every $(x, y)$ point, point clouds allow having more than one height value, which enhances the 3D representation of the crops. Meanwhile DSMs have been used in vineyards for vine volume and height calculation [13-16] and point clouds have been reported for vineyard detection and estimation of its macro-structure [17,18], for measuring vine height [19], and for adding geometric traits to the spectral information for disease detection [20]. Another application of the UAV-generated $3 \mathrm{D}$ models of orchards is their use as a source of information for simulating and evaluating routes for agricultural robots [21].

Pádua et al. [16] monitored the vegetation growing cycle of a vineyard using UAV-derived imagery and DSM, which allowed them to estimate the vineyard area and volume in nine distinct dates. Although it was not their main objective, they detected the changes in area and volume caused by leaf removal operations. However, they were not able to distinguish any change in the vines after a shoot thinning treatment as "much of this operation is performed in the grapevine canopy understory, and the DSM only represented the upper part of the vine. Consequently, it is clear that a methodology for the detection and inspection of the most frequent canopy management operations should be able of identifying changes in the vines at different heights." Escolà et al. [22] created width profiles at different heights for vineyards and olive and fruit trees, using a tractor-mounted scanning LIDAR and point clouds. However, to the best of our knowledge, photogrammetric point clouds generated from UAV imagery have not been applied to quantify the differences of the vine dimensions after and before canopy management operations. Point clouds representing woody crops include a high amount of information, whose processing and interpretation in a timely way requires advanced and automated image analysis procedures. Object Based Image Analysis (OBIA) techniques have proved its efficiency 
and accuracy in the extraction of information from high-resolution images [23]. OBIA algorithms have been applied to UAV 3D datasets to detect canopy management operations in lychee [24] and different pruning strategies in olive [25], but they used DSM as input for the algorithms. However, in the last years, OBIA procedures are being also used for processing non-image remote sensing datasets, such as point clouds. For example, LIDAR point clouds have been analyzed with OBIA techniques for building detection [26-28] and forest inventory [29-32]; and photogrammetric point clouds from UAV imagery have been successfully used for the 3D characterization of woody crops such as almond [5] and olive trees [33].

The objective of this work setup was to assess the possibility of detecting canopy management operations using UAV photogrammetry. For achieving this objective, a UAV equipped with an RGB digital camera was used to acquire images with high overlap over different canopy management experiments in four vineyards. These images were used for generating photogrammetric point clouds of the vineyards before and after the canopy management operations. An automated OBIA algorithm was applied to the point clouds for extracting geometric information from every vine, including its width at different heights. The UAV derived-data were analyzed using two approaches to: (1) determine whether the comparison of the vine dimensions after and before the canopy management operations allowed their detection; and (2) study the vine dimensions solely after the operations and assess the possibility of detecting these operations using only the vine dimensions estimated from the flight after them. To the best of our knowledge, this is the first time that photogrammetric point clouds have been used for evaluating a set of canopy management operations in agricultural fields, and it is also the first time that width profiles at different heights have been extracted from photogrammetric point clouds representing a woody crop.

\section{Materials and Methods}

\subsection{Study Sites}

The experiment was carried out in a set of commercial vineyards located in Northern Spain, two in Navarra (named Azagra, Az; Traibuenas, Tr) and two in La Rioja (named Ausejo, Au-1 and Au-2). The grape variety was Tempranillo. The vines were trellised as a vertical-shoot positioned cordon royat, and vineyards were chosen as representative of the typical growing conditions in the region, their main characteristics being summarized in Table 1.

Table 1. Information about the study fields.

\begin{tabular}{|c|c|c|c|c|c|}
\hline $\begin{array}{l}\text { Field } \\
\text { Name }\end{array}$ & Location & $\begin{array}{l}\text { Planting } \\
\text { Distance }\end{array}$ & $\begin{array}{l}\text { Slope } \\
\text { Along } \\
\text { the Vine } \\
\text { Rows (\%) }\end{array}$ & Soil Management & $\begin{array}{l}\text { Canopy Management } \\
\text { Practices Evaluated }^{1}\end{array}$ \\
\hline $\mathrm{Az}$ & $\begin{array}{c}\text { Azagra } \\
\text { (NA, Spain) }\end{array}$ & $3.0 \times 1.3 \mathrm{~m}$ & 2.62 & $\begin{array}{c}\text { Bare soil, } \\
\text { mechanical tillage } \\
\text { (A) + herbicide (U) }\end{array}$ & Shoot thinning \\
\hline $\operatorname{Tr}$ & $\begin{array}{l}\text { Traibuenas } \\
\text { (NA, Spain) }\end{array}$ & $3.0 \times 1.0 \mathrm{~m}$ & 4.95 & $\begin{array}{l}\text { Spontaneous low } \\
\text { vigour cover crop } \\
\text { (A) + herbicide (U) }\end{array}$ & $\begin{array}{l}\text { Leaf removal mode } \\
\qquad(1 \text { vs } 2 \text { sides })\end{array}$ \\
\hline $\mathrm{Au}-1$ & $\begin{array}{c}\text { Ausejo } \\
\text { (LO, Spain) }\end{array}$ & $2.4 \times 1.0 \mathrm{~m}$ & 5.54 & $\begin{array}{l}\text { Spontaneous low } \\
\text { vigour uneven } \\
\text { cover crop }(\mathrm{A})+ \\
\text { herbicide }(\mathrm{U})\end{array}$ & $\begin{array}{l}\text { Leaf removal intensity } \\
\text { Shoot trimming } \\
\text { intensity }\end{array}$ \\
\hline $\mathrm{Au}-2$ & $\begin{array}{c}\text { Ausejo } \\
\text { (LO, Spain) }\end{array}$ & $2.4 \times 1.0 \mathrm{~m}$ & 4.14 & $\begin{array}{l}\text { Spontaneous low } \\
\text { vigour uneven } \\
\text { cover crop }(\mathrm{A})+ \\
\text { herbicide }(\mathrm{U})\end{array}$ & Shoot trimming \\
\hline
\end{tabular}

NA: Navarra; LO: La Rioja; A: vineyard alleys; U: area under the vine. ${ }^{1}$ Details of canopy management operations provided in Table 2. 
Table 2. Information about locations, canopy management operations, and UAV flights performed at the study vineyards.

\begin{tabular}{|c|c|c|c|c|c|c|c|}
\hline $\begin{array}{c}\text { Canopy Management } \\
\text { Operation }\end{array}$ & $\begin{array}{c}\text { Factor } \\
\text { Evaluated }\end{array}$ & Location & $\begin{array}{c}\text { Treatments and } \\
\text { Abbreviation }\end{array}$ & $\begin{array}{l}\text { No. } 1 \text { M-Long } \\
\text { Row Sections }\end{array}$ & $\begin{array}{l}\text { Treatment and } \\
\text { Flight Date }\end{array}$ & $\begin{array}{c}\text { (Before and } \\
\text { Before }\end{array}$ & $\begin{array}{c}\text { Flights } \\
\text { After Canopy Operation) } \\
\text { After }\end{array}$ \\
\hline $\begin{array}{c}\text { Shoot thinning } \\
\text { (STh) }\end{array}$ & $\begin{array}{c}\text { STh } \\
\text { detection }\end{array}$ & $\begin{array}{l}\text { Azagra (Az) } \\
\text { Navarra }\end{array}$ & $\begin{array}{l}\text { Thinned (Th) } \\
\text { Control (C) }\end{array}$ & $\begin{array}{l}20 \\
20\end{array}$ & 05-17-2018 & $x$ & $x$ \\
\hline \multirow[t]{2}{*}{$\begin{array}{l}\text { Leaf removal } \\
\qquad(\mathrm{LR})\end{array}$} & LR mode & $\begin{array}{l}\text { Traibuenas }(\mathrm{Tr}) \\
\text { Navarra }\end{array}$ & $\begin{array}{c}1 \text { side (LR-1s) } \\
2 \text { sides (LR-2s) } \\
\text { Control (C) }\end{array}$ & $\begin{array}{l}108 \\
108 \\
108\end{array}$ & 08-01-2018 & $x$ & $x$ \\
\hline & LR intensity & $\begin{array}{c}\text { Ausejo }(\mathrm{Au}-1) \mathrm{La} \\
\text { Rioja }\end{array}$ & $\begin{array}{c}\text { Low intensity } \\
\text { (LR-LI) } \\
\text { High intensity } \\
\text { (LR-HI) } \\
\text { Control }\end{array}$ & $\begin{array}{l}12 \\
12\end{array}$ & 06-20-2018 & $x$ & $x$ \\
\hline \multirow[t]{2}{*}{$\begin{array}{l}\text { Shoot trimming } \\
\text { (ST) }\end{array}$} & ST detection & $\begin{array}{c}\text { Ausejo (Au-2) La } \\
\text { Rioja }\end{array}$ & $\begin{array}{c}\text { Shoot trimming } \\
\text { (ST) } \\
\text { Control (C) }\end{array}$ & $\begin{array}{l}160 \\
160\end{array}$ & $\begin{array}{l}\text { Treatment: } \\
\text { 06-12-2018 } \\
\text { Flight: } \\
06-20-2018\end{array}$ & & $x$ \\
\hline & ST intensity & $\begin{array}{c}\text { Ausejo (Au-1) La } \\
\text { Rioja }\end{array}$ & $\begin{array}{c}\text { Low intensity } \\
\text { (ST-LI) } \\
\text { High intensity } \\
\text { (ST-HI) } \\
\text { Control }\end{array}$ & $\begin{array}{l}12 \\
12\end{array}$ & 06-20-2018 & $x$ & $x$ \\
\hline
\end{tabular}




\subsection{UAV Flights and Image Acquisition}

Remote images were acquired with a UAV for the generation of the 3D point clouds used for the geometric characterization of the vines. Images were taken with a Sony ILCE-6000 (Sony Corporation, Tokyo, Japan) camera equipped with a $20 \mathrm{~mm}$ fixed focal length lens. The UAV used in these works was a quadcopter model MD4-1000 (microdrones GmbH, Siegen, Germany), to which the camera was attached facing downward for nadir capture. The flight routes were designed at $30 \mathrm{~m}$ flight height above ground, with a side lap of $60 \%$, and a forward lap of $89 \%$. The flights were performed around midday on sunny days with wind speeds below $3 \mathrm{~m} \cdot \mathrm{s}^{-1}$. Similar flight configurations have been successfully used for the creation of 3D point clouds representing woody crops in previous works [5,33].

\subsection{Experiment Description}

\subsubsection{Shoot Thinning}

The shoot thinning experiment was carried out on 17th of May 2018 on the Az vineyard. Thinning was done following winery specifications for this operation. The study area comprised $1.2 \mathrm{ha}$, where alternate pair of rows were shoot-thinned or kept untouched as control. For evaluation, 10 replicates of two consecutive vines were marked and georeferenced along the vineyard, and their canopy characteristics were determined. Before thinning, the average number of shoots per vine was 22.7, and thinning decreased that value to 9.7 shoots per vine. Figure 1 shows images of some vines after the shoot thinning and some unthinned vines belonging to the control treatment. Leaf area before and after thinning was estimated after establishing an allometric relationship between individual shoot length $(\mathrm{SL}, \mathrm{cm})$ and its leaf area $\left(\mathrm{LA}, \mathrm{cm}^{2}\right)$ following the procedure detailed in [34] [LA $=0.132 \cdot \mathrm{SL}^{2}$ $\left.+9.217 \cdot \mathrm{SL}+11.68, \mathrm{R}^{2}=0.87, \mathrm{n}=50, P<0.001\right)$. The average leaf area before shoot thinning was $0.98 \mathrm{~m}^{2}$ vine $^{-1}$, and $0.52 \mathrm{~m}^{2}$ vine $^{-1}$ afterwards.
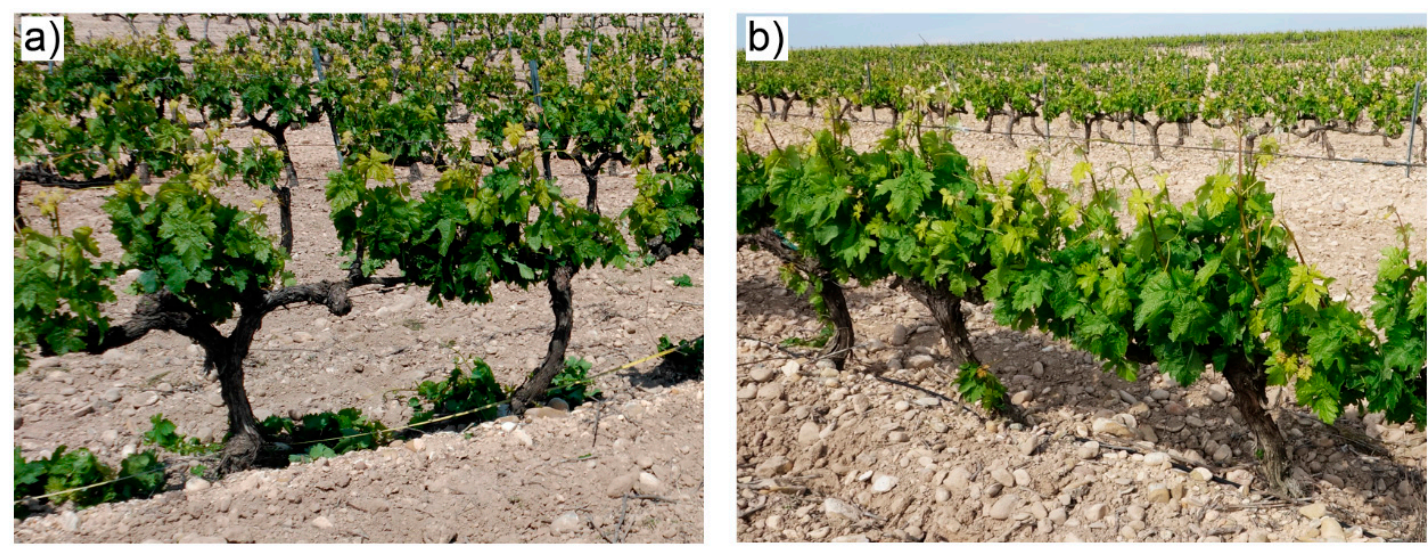

Figure 1. Images of the vineyard in Azagra after shoot thinning: (a) shoot thinned vines, (b) control vines.

\subsubsection{Leaf Removal}

Leaf removal was evaluated in two fields, $\operatorname{Tr}$ (leaf removal mode) and Au-1 (leaf removal intensity) and operations were made as follows:

- $\quad$ Leaf removal mode (1 vs. 2 sides)

The experiment to evaluate the detection of leaf removal mode was carried out in Tr vineyard 1st August 2018. In that field, leaf removal was done in two different modes; leaf removal in one side (LR-1s) of the row and leaf removal in the two sides (LR-2s). In both cases, the leaves from the basal $40 \mathrm{~cm}$ of the shoots were removed, irrespective of whether they belonged to the main shoot or to laterals (Figure 2). For each treatment, leaves were removed in nine replicates of 12 vines each, leaving 
nine additional replicates where the vines remained untouched as a control. Figure 2 shows the general aspect of the canopy management treatments. Total leaf area before removal was estimated through allometric relationships performed in 54 vines, being, as an average, $3.39 \mathrm{~m}^{2}$ vine $^{-1}$. The amount of removed leaf area was measured in 18 vines per treatment, being as an average $0.99 \mathrm{~m}^{2}$ vine $^{-1}$ in LR-1s and $1.82 \mathrm{~m}^{2}$ vine $^{-1}$ in LR-2s.
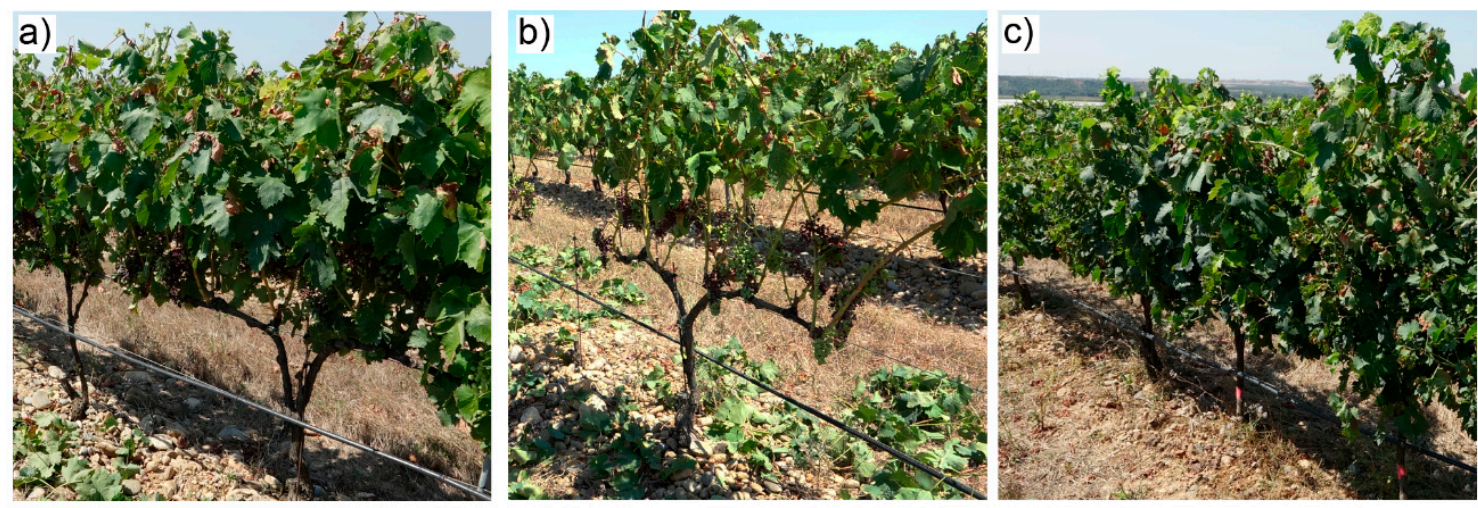

Figure 2. Pictures after leaf removal mode experiment in Traibuenas: (a) leaves removed from one side (LR-1s), (b) two sides (LR-2s), (c) control vines.

\section{- Leaf removal intensity}

The evaluation of the potential of UAV-acquired photogrammetric point clouds to assess leaf removal intensity was carried out in the Au-1 vineyard on 20th of June 2018. Two intensities of leaf removal were tested, differing on the fraction of the shoot that was defoliated. Thus, in low intensity leaf removal vines (LR-LI), all the leaves in the basal $40 \mathrm{~cm}$ of the shoot were removed, whereas in high intensity leaf removal (LR-HI), leaves were removed from the basal $70 \mathrm{~cm}$. In both intensities, all leaves were removed, irrespective of whether they belonged to the main shoot or to laterals (Figure 3).
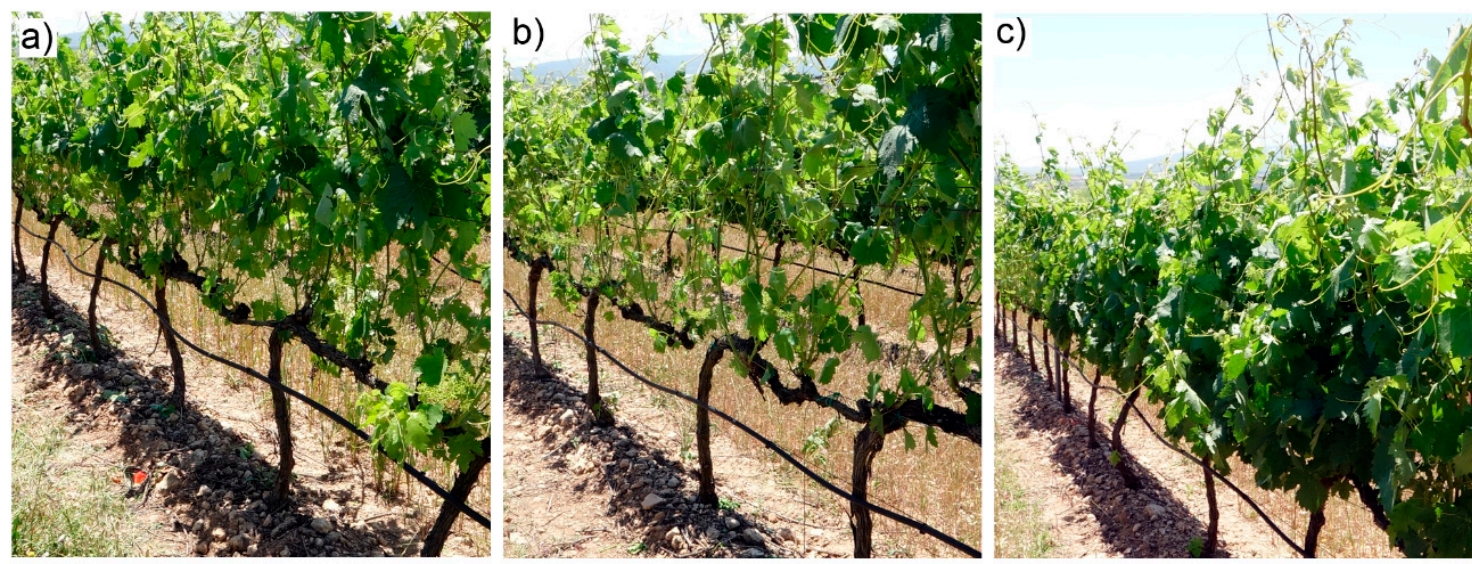

Figure 3. Pictures after leaf removal intensity experiment in Ausejo: (a) low intensity leaf removal (LR-LI), (b) high intensity leaf removal (LR-HI), (c) control vines.

Two replicates of six vines where established for each leaf removal intensity, and an additional two replicates of six untouched vines were used as control. Vine leaf area was estimated through allometric relationships before leaf removal in 24 vines, being $3.42 \mathrm{~m}^{2}$ vine $^{-1}$ on average. The leaves removed from 12 vines per treatment were collected, and their leaf area was measured, accounting for $1.12 \mathrm{~m}^{2}$ vine $^{-1}$ in LR-LI and for $1.65 \mathrm{~m}^{2}$ vine $^{-1}$ in LR-HI on average. 


\subsubsection{Shoot Trimming}

Shoot trimming was evaluated in two fields: Au-2 (shoot trimming detection) and Au-1 (shoot trimming intensity). The main difference was that whereas in Au- 1 leaves were removed the same day the flights took place, and therefore, canopy characteristics and UAV imaging could be acquired before and after the operation, in Au-2 leaf removal had already been performed some days before (Table 2 for details).

- Shoot trimming detection

Shoot trimming was applied to 10 replicates of 16 vines, whereas another 16 vines were used as control and were left untreated (Figure 4). Leaf area before trimming was measured in 20 vines, being as $2.62 \mathrm{~m}^{2}$ vine $\mathrm{e}^{-1}$ on average. The trimmed shoots were collected and their leaf area calculated, accounting for $0.87 \mathrm{~m}^{2}$ vine $^{-1}$.
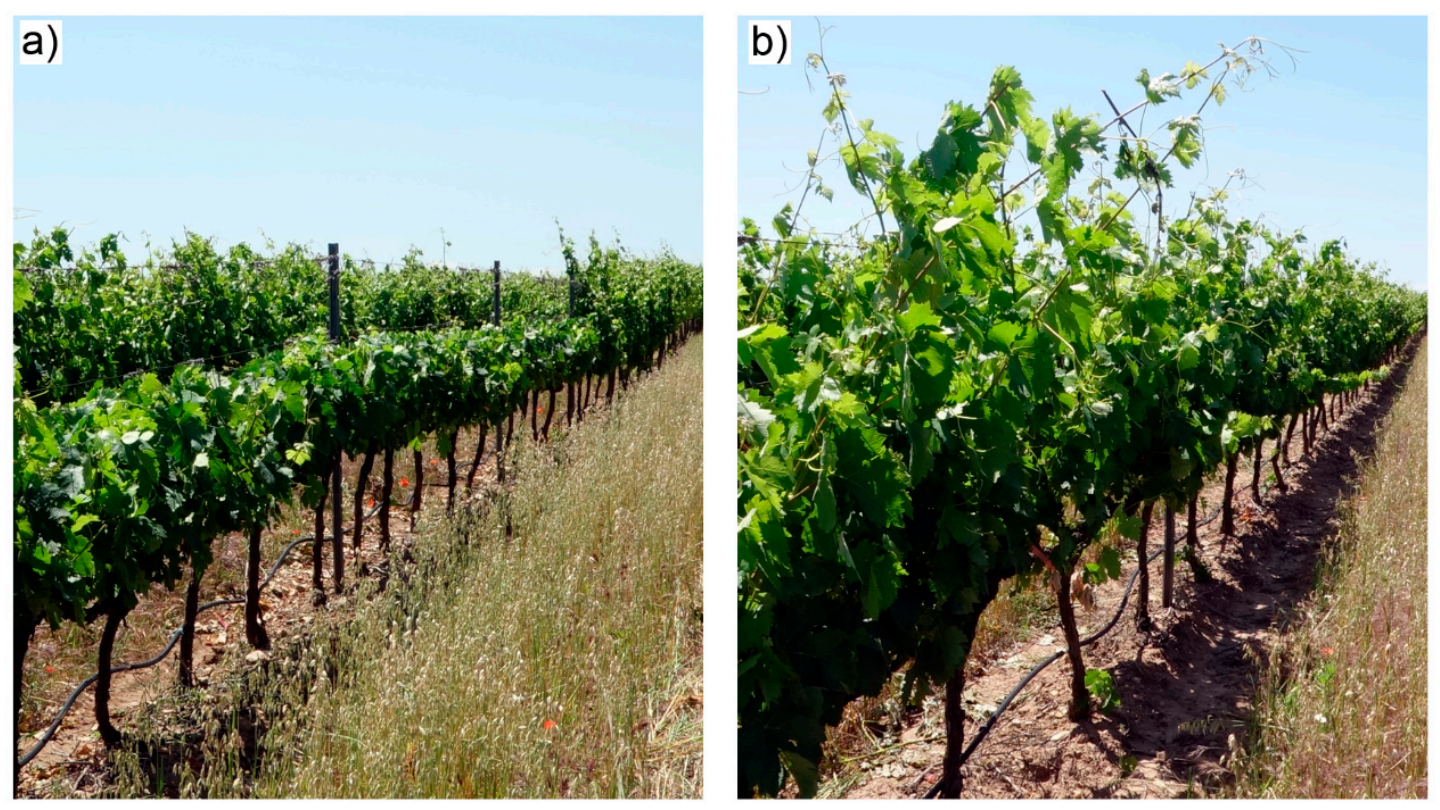

Figure 4. Pictures after the shoot trimming detection experiment in Ausejo: (a) Shoot trimmed vines, (b) control vines.

- Shoot trimming intensity

The dates and experimental design of this experiment follows the same structure detailed for leaf removal in Au-1, as they were performed at the same time and in adjacent vines. Two intensities of shoot trimming were tested, differing on the length of the shoot that was kept untrimmed. On the one side, in low intensity shoot-trimmed vines (ST-LI), shoots were cut $80 \mathrm{~cm}$ above the cordon, whereas for high intensity shoot-trimmed vines (ST-HI) shoots were cut $45 \mathrm{~cm}$ above the cordon (Figure 5). Leaf area before trimming was measured in 24 vines, being as an average $3.36 \mathrm{~m}^{2}$ vine $^{-1}$. The trimmed shoots were collected, and their leaf area calculated, accounting for $1.24 \mathrm{~m}^{2}$ vine ${ }^{-1}$ in ST-LI vines and for $1.87 \mathrm{~m}^{2}$ vine $^{-1}$ in ST-HI vines. 

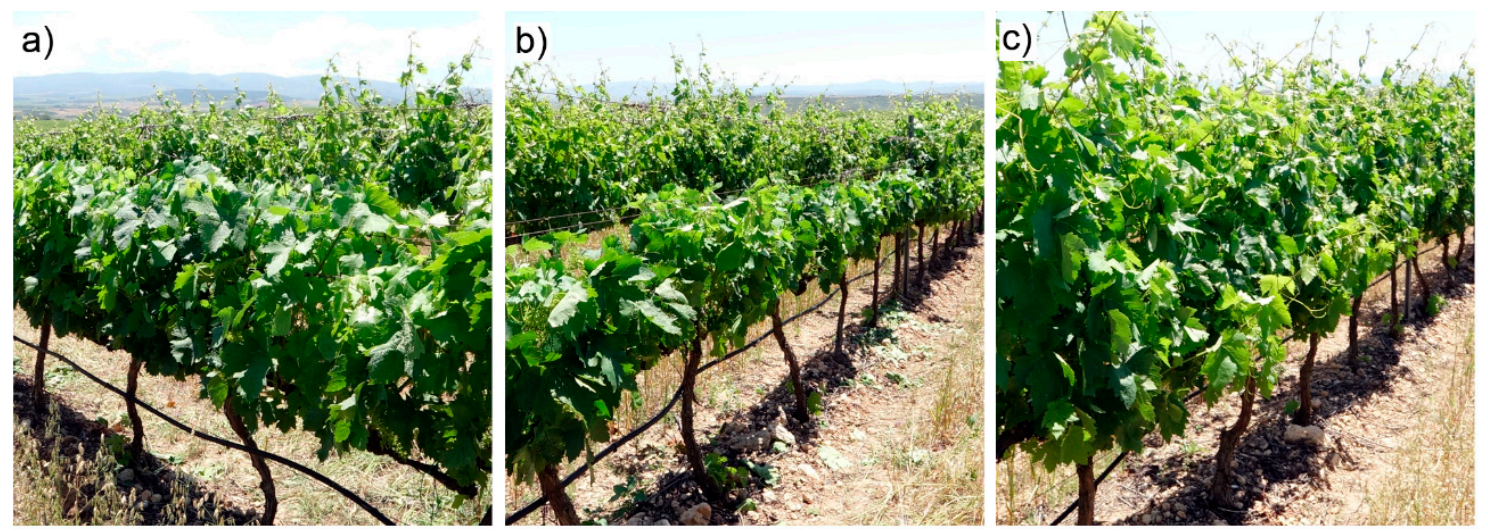

Figure 5. Pictures after shoot trimming intensity experiment in Ausejo: (a) low intensity shoot trimming (ST-LI), (b) high intensity shoot (ST-HI), (c) control vines.

\subsection{Point Cloud Generation}

Photogrammetric and computer vision techniques were applied to the UAV-imagery for the generation of the $3 \mathrm{D}$ point clouds used for the geometric characterization of the vines. The software used for the creation of the 3D point clouds was Agisoft PhotoScan Professional Edition (Agisoft LLC, St. Petersburg, Russia) version 1.5 .3 build 8469 . The photogrammetric process only required human intervention for the localization of five ground control points, georeferenced in each field with a real time kinematic (RTK) GPS linked to a reference station from the GNSS network from the National Geographic Institute, Spain. The estimated accuracy of the GNSS-RTK system was $0.02 \mathrm{~m}$ in planimetry and $0.03 \mathrm{~m}$ in altimetry. More details about the process can be found in [5]. The point clouds had a mean point density of 15,431 points $\mathrm{m}^{-2}$, and were stored in "las" format, a public file format for the interchange of 3D point cloud data. Much lower point cloud densities around 2000 [5] and 4000 points $\cdot \mathrm{m}^{-2}$ [33] have been successfully used for 3D crop characterization in other woody crops.

\subsection{OBIA Algorithm}

The OBIA algorithm for the characterization of grapevine rows was created using Cognition Network Language in eCognition Developer 9 software (Trimble GeoSpatial, Munich, Germany). The detection of the vines was based on the measurement of their height over the soil, and a voxel method was used for vine volume estimation. These approaches have been tested in previous algorithms, and developed and successfully validated for point cloud analysis in other woody crops, such as almond [5] and olive [33]. In this work, the above-mentioned methodologies have been adapted to the vineyard structure, which is organized in narrow vine rows. The detection and segmentation of vine rows is adapted from a previous work were DSM instead of points clouds were used for the 3D characterization of vines [14]. As the algorithms for almond and olive [5,33], the algorithm for vineyard $3 \mathrm{D}$ analysis is fully automatic with no need of user intervention. It can be divided in the following steps and the only inputs used were the point cloud and a shapefile delimiting the field studied:

1. Digital terrain model (DTM) generation: the point cloud is segmented using a chessboard pattern with a $2 \mathrm{~m}$ side. The average height of the points belonging to the $15^{\text {th }}$ lowest percentile in each square, which are assumed to belong to the soil, is stored in an image layer (Figure 6a) that will be used as DTM. This methodology for DTM creation has been validated in fruit orchards with no understory vegetation [5,33], and it has been used in these vineyards since they only have some spontaneous low vigor herbaceous cover (Table 1). The use of a DTM allows taking into account the slope of the fields (Table 1) when measuring the height of the vines.

2. Vineyard classification: the point cloud is segmented using a chessboard pattern with $0.1 \mathrm{~m}$ side. All the squares containing points whose height over the DTM was higher than $0.5 \mathrm{~m}$ are classified 
as vineyard (Figure 6a). The points inside the areas classified as vineyard, and with a height over the DTM higher than $0.5 \mathrm{~m}$ are stored in a temporal point cloud.

3. Point cloud slicing: the new point cloud is divided in slices parallel to the DTM with $0.1 \mathrm{~m}$ height. Considering that the point cloud was previously divided in $0.1 \mathrm{~m}$ squares, it results that the vine point cloud is divided in 3D pixels (voxels) of $0.1 \mathrm{~m}$ side. Phattaralerphong et al. [35] reported that the optimal voxel sizes for crown volume estimates ranged from 0.1 to $0.4 \mathrm{~m}$. The size of the voxel is linked with the accuracy of the crown volume estimate [36-38] and large voxel sizes are related with greater estimation accuracies. However, choosing an excessively large voxel side leads to the generation of few voxels, which results in too coarse description of the canopy. Thus, taking into account the size of the vine rows, $0.1 \mathrm{~m}$ was selected as the optimal voxel size. A set of image layers is created with a resolution of $0.1 \mathrm{~m}$, storing in every pixel of each layer the number of voxels containing points belonging to the vine that had the same $x, y$ coordinates than the pixel.

4. Vine row detection and segmentation: for the vineyard to be characterized, the vine rows must be detected and segmented, as the absolute and relative coordinates of these segments are used to refer to the data extracted by the algorithm. Once all the vines are classified, their orientation is automatically calculated and it is used to rotate the image. By doing this, the image shows the rows horizontally, which eases the following processes. The first one is the creation of an upper level of analysis, segmented in horizontal strips with a width of $0.5 \mathrm{~m}$. Then, the algorithm looks for the strip with the highest percentage of vine at the lowest level and classifies it as "vine row." Next, taking into account the distance between rows, the algorithm searches for the remaining lines with high percentage of vine at the lowest level, and classifies them as "vine rows." Finally, the "vine rows" are divided in segments with a user-defined length, which was $0.1 \mathrm{~m}$ (Figure $6 \mathrm{~b}$ ) in this case.

5. Vine segments characterization: the maximum height of every segment is calculated by comparing the point height with the DTM height (Figure 6c). The segment area is extracted from the classification performed in the second step of the algorithm. For every one of the vine segments and knowing the voxel volume $\left(0.1 \times 0.1 \times 0.1 \mathrm{~m}^{3}\right)$, the volume is calculated taking into account the number of voxels including vine points that are under the vine segment for all the slices created in step 3 (Figure $5 \mathrm{~d}$ ). The maximum width of the segment at $0.1 \mathrm{~m}$-height intervals is extracted from the slices created in step 3. For both the width and volume calculation, the space between the sides of the vine is supposed to be full of vegetation (Figure $5 \mathrm{~d}$ ). The data for each segment are associated with its coordinates and relative position inside the vine row.

The vine rows were divided in $0.1 \mathrm{~m}$ length segments to achieve a detailed characterization of its geometrical properties. However, clusters of 10 segments were created to achieve 1-m long groups that could be assimilated to individual vines. In the experiments where the results from two flights were compared, this grouping could also help to deal with subtle changes in the shoot position caused by the corresponding canopy management, which could affect the matching of the segments for the comparison between flights. In the grouping of the segments, the sum of the values was calculated for volume and area, while the maximum was computed for the rest of the features (height, total width, and width at different heights). The segment length used in this work was that recommended by $[39,40]$ in the analysis of LIDAR point clouds acquired using an on-ground vehicle for analyzing vineyards. 

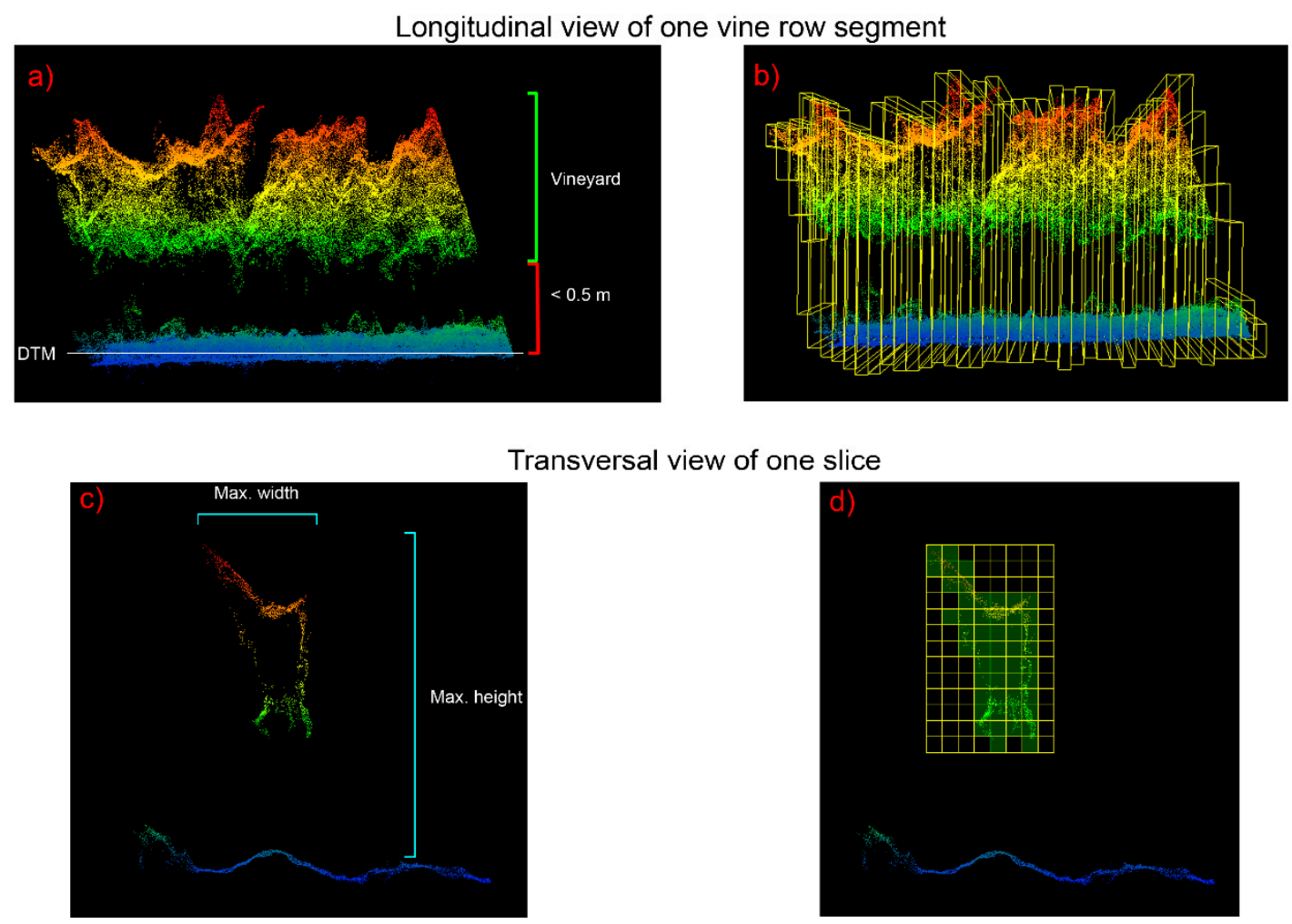

Figure 6. Graphical summary of the main steps of the Object Based Image Analysis (OBIA) algorithm for vineyard characterization. (a) Side view of the point cloud of one segment of vine row. The height threshold for vineyard classification is showed. (b) Boxes showing the slicing applied to the vine row. (c) Front view of one of the vine slices from $6 \mathrm{~b}$. (d) Division of the previous slice in voxels.

\subsection{Data Analysis}

The changes in the vine dimensions after the canopy management operations that had been estimated with UAV-acquired photogrammetric point clouds were analyzed using a paired T-test (at $p=0.05)$. In this analysis, the difference among the features of each 1-m long segment before and after the canopy management was calculated for the different treatments, with positive values indicating a decrease, and negative values an increase in the vine dimensions of the studied feature. In order to assess the second objective of the work, the vine dimensions after the canopy management were analyzed using a Student's $T$ test (at $p=0.05$ ) to look for significant differences among treatments. All the statistical analysis were carried out using JMP software version 10.0.0 (SAS, Cary, NC, USA), the charts were created using R, version 3.5.2, with the R package "ggplot2" [41].

\section{Results}

\subsection{Vine Dimensions after the Canopy Operation Experiments}

The results reported in this section aimed to study if the comparison between the data from the flights before and after the canopy treatments is suitable for detecting the execution of the canopy management operations.

\subsubsection{Shoot Thinning}

The shoot thinning treatment led to a decrease of all the studied vine features, with the exception of vine height and of width at highest height interval (1.2-1.3 m) (Table 3). The greatest mean changes in width $(0.7 \pm 0.09)$ were detected at around $1 \mathrm{~m}$ height, where the canopy was the widest before shoots were thinned. On the contrary, there were no significant changes in the dimensions of the control vines in the shoot thinning experiment, with all the mean variations being close to zero (Table 3). 
Table 3. Mean and standard deviation of vine dimension changes after the shoot thinning experiment at Azagra. The table is divided in two parts: (1) changes in main dimensions of the vine, (2) changes in the width at different height intervals. Values followed by an asterisk are indicative of significant differences among the vine dimensions before and after the canopy management (paired $T$-test at $p=$ 0.05).

\begin{tabular}{ccccc}
\hline & Variable & Control & \multicolumn{2}{c}{ Shoot-Thinned } \\
\hline & Volume $\left(\mathrm{m}^{3}\right)$ & $0.00 \pm 0.02$ & $0.03 \pm 0.03$ & $*$ \\
Change in vine & Height $(\mathrm{m})$ & $-0.01 \pm 0.06$ & $0.03 \pm 0.07$ & \\
dimensions & Area $\left(\mathrm{m}^{2}\right)$ & $0.00 \pm 0.03$ & $0.06 \pm 0.05$ & $*$ \\
& Max width $(\mathrm{m})$ & $0.00 \pm 0.04$ & $0.04 \pm 0.06$ & $*$ \\
\hline & $0.5-0.6$ & $-0.03 \pm 0.12$ & $0.05 \pm 0.10$ & $*$ \\
Change in & $0.6-0.7$ & $-0.01 \pm 0.07$ & $0.04 \pm 0.08$ & $*$ \\
width $(\mathrm{m})$, at & $0.7-0.8$ & $0.00 \pm 0.05$ & $0.05 \pm 0.07$ & $*$ \\
height interval & $0.8-0.9$ & $0.00 \pm 0.04$ & $0.05 \pm 0.07$ & $*$ \\
& $0.9-1.0$ & $0.02 \pm 0.05$ & $0.05 \pm 0.07$ & $*$ \\
& $1.0-1.1$ & $-0.03 \pm 0.08$ & $0.07 \pm 0.09$ & $*$ \\
& $1.1-1.2$ & $0.04 \pm 0.13$ & $0.06 \pm 0.08$ & $*$ \\
\hline
\end{tabular}

\subsubsection{Leaf Removal}

\section{- $\quad$ Leaf removal mode}

Table 4 summarizes the results for the assessment of vine dimension changes in the experiment with different modes of leaf removal at Traibuenas vineyard. All the geometric parameters evaluated applying the OBIA algorithm to the vineyard point clouds registered a significant decrease between the pre- and post-treatment flights at Traibuenas vineyard, except for the width at 2.0-2.1 $\mathrm{m}$ for the Tr-2S. Although these width changes were observed to occur in all treatments, including control vines, the changes in width for the intervals between 0.6 and $1.1 \mathrm{~m}$ (where the leaves were removed) followed an increasing trend, the smallest changes being observed for control vines, followed by LR-1s, and the maximum changes being observed for LR-2s.

Table 4. Mean and standard deviation of vine dimensions change after the leaf removal experiment at Traibuenas vineyard. The table is divided in two parts: (1) changes in main dimensions of the vine, (2) changes in the width at different height intervals. Values followed by an asterisk are indicative of significant differences among the vine dimensions before and after the canopy management (paired T-test at $p=0.05)$.

\begin{tabular}{ccccccc}
\hline & Variable & Control & $\begin{array}{c}\text { One Side } \\
\text { (LR-1s) }\end{array}$ & $\begin{array}{c}\text { Two Sides } \\
\text { (LR-2s) }\end{array}$ \\
\hline Change in vine & Volume $\left(\mathrm{m}^{3}\right)$ & $0.09 \pm 0.09$ & $0.13 \pm 0.09$ & $*$ & $0.16 \pm 0.09$ & $*$ \\
dimensions & Areaght $(\mathrm{m})$ & $0.04 \pm 0.06$ & $0.04 \pm 0.06$ & $*$ & $0.05 \pm 0.08$ & $*$ \\
& Max width $(\mathrm{m})$ & $0.02 \pm 0.05$ & $0.05 \pm 0.05$ & $*$ & $0.06 \pm 0.05$ & $*$ \\
& $0.5-0.6$ & $0.05 \pm 0.08$ & $0.06 \pm 0.08$ & $*$ & $0.06 \pm 0.09$ & $*$ \\
\hline Change in & $0.6-0.7$ & $0.08 \pm 0.17$ & $0.09 \pm 0.20$ & $*$ & $0.08 \pm 0.21$ & $*$ \\
width (m), at & $0.7-0.8$ & $0.08 \pm 0.20$ & $0.16 \pm 0.19$ & $*$ & $0.18 \pm 0.19$ & $*$ \\
height interval & $0.8-0.9$ & $0.08 \pm 0.23$ & $0.17 \pm 0.21$ & $*$ & $0.27 \pm 0.24$ & $*$ \\
& $1.0-1.0$ & $0.08 \pm 0.24$ & $0.16 \pm 0.21$ & $*$ & $0.24 \pm 0.21$ & $*$ \\
& $1.1-1.2$ & $0.03 \pm 0.14$ & $0.12 \pm 0.18$ & $*$ & $0.15 \pm 0.22$ & $*$ \\
& $1.2-1.3$ & $0.04 \pm 0.10$ & $0.09 \pm 0.15$ & $*$ & $0.08 \pm 0.14$ & $*$ \\
& $1.3-1.4$ & $0.03 \pm 0.09$ & $0.05 \pm 0.10$ & $*$ & $0.04 \pm 0.09$ & $*$ \\
& $1.4-1.5$ & $0.05 \pm 0.11$ & $0.04 \pm 0.09$ & $*$ & $0.06 \pm 0.09$ & $*$ \\
\hline
\end{tabular}


Table 4. Cont.

\begin{tabular}{cccccc}
\hline Variable & Control & $\begin{array}{c}\text { One Side } \\
\text { (LR-1s) }\end{array}$ & \multicolumn{2}{c}{$\begin{array}{c}\text { Two Sides } \\
\text { (LR-2s) }\end{array}$} \\
\hline $1.5-1.6$ & $0.07 \pm 0.12$ & $0.06 \pm 0.15$ & $*$ & $0.09 \pm 0.15$ & $*$ \\
$1.6-1.7$ & $0.08 \pm 0.15$ & $0.09 \pm 0.16$ & $*$ & $0.09 \pm 0.17$ & $*$ \\
$1.7-1.8$ & $0.09 \pm 0.16$ & $0.09 \pm 0.17$ & $*$ & $0.12 \pm 0.21$ & $*$ \\
$1.8-1.9$ & $0.05 \pm 0.13$ & $0.10 \pm 0.20$ & $*$ & $0.09 \pm 0.19$ & $*$ \\
$1.9-2.0$ & $0.04 \pm 0.13$ & $0.03 \pm 0.10$ & $*$ & $0.03 \pm 0.12$ & $*$ \\
$2.0-2.1$ & $0.01 \pm 0.04$ & $0.01 \pm 0.04$ & $*$ & $0.01 \pm 0.09$ & \\
\hline
\end{tabular}

- Leaf removal intensity

Table 5 summarizes the results for the assessment of vine dimension changes in the experiment with different intensities of leaf removal carried out at Ausejo-1. Although changes in vine dimensions were detected for all treatments, including control vines, for the latter, changes occurred only in a few features related with the width. However, removing one vine that was detected as unusually wide in the first flight, only two of the significant differences would remain (width at intervals 1.4-1.5, 1.6-1.7, and 1.8-1.9 m). Vines under the lower intensity leaf removal (LR-LI) treatment suffered significant changes in their volume, area, and width at different height intervals, with these changes being larger (around $0.2 \mathrm{~m}$ ) at the height intervals where the leaves were removed $(0.9-1.3 \mathrm{~m})$. The changes observed for high intensity leaf removal (LR-HI) treatment were similar, although it also affected the vine height at higher width intervals.

Table 5. Mean and standard deviation of vine dimension changes after low and high intensity leaf removal experiment at Ausejo-1. The table is divided in two parts: (1) changes in main dimensions of the vine, (2) changes in the width at different height intervals. Values followed by an asterisk are indicative of significant differences among the vine dimensions before and after the canopy management (paired $T$-test at $p=0.05$ ).

\begin{tabular}{|c|c|c|c|c|c|c|c|}
\hline & Variable & Control & & $\begin{array}{c}\text { Low Intensity } \\
\text { Leaf Removal } \\
\text { (LR-LI) }\end{array}$ & & $\begin{array}{l}\text { High Intensity } \\
\text { Leaf Removal } \\
\text { (LR-HI) }\end{array}$ & \\
\hline \multirow{4}{*}{$\begin{array}{l}\text { Change in } \\
\text { vine } \\
\text { dimensions }\end{array}$} & Volume $\left(\mathrm{m}^{3}\right)$ & $0.02 \pm 0.09$ & & $0.13 \pm 0.12$ & $*$ & $0.16 \pm 0.10$ & * \\
\hline & Height (m) & $0.01 \pm 0.13$ & & $0.03 \pm 0.17$ & & $0.11 \pm 0.19$ & * \\
\hline & Area $\left(\mathrm{m}^{2}\right)$ & $0.05 \pm 0.08$ & * & $0.10 \pm 0.05$ & * & $0.17 \pm 0.05$ & * \\
\hline & Max width (m) & $0.07 \pm 0.12$ & * & $0.09 \pm 0.10$ & * & $0.19 \pm 0.08$ & * \\
\hline \multirow{17}{*}{$\begin{array}{l}\text { Change in } \\
\text { width (m), } \\
\text { at height } \\
\text { interval }\end{array}$} & $0.5-0.6$ & $-0.01 \pm 0.18$ & \multirow{9}{*}{ * } & $-0.09 \pm 0.13$ & * & $0.04 \pm 0.11$ & \\
\hline & $0.6-0.7$ & $0.03 \pm 0.20$ & & $-0.11 \pm 0.13$ & * & $-0.02 \pm 0.19$ & \\
\hline & $0.7-0.8$ & $-0.01 \pm 0.18$ & & $-0.06 \pm 0.18$ & & $-0.03 \pm 0.25$ & \\
\hline & $0.8-0.9$ & $0.18 \pm 0.29$ & & $0.04 \pm 0.22$ & & $0.02 \pm 0.26$ & \\
\hline & $0.9-1.0$ & $-0.01 \pm 0.14$ & & $0.18 \pm 0.17$ & * & $0.15 \pm 0.14$ & * \\
\hline & $1.0-1.1$ & $0.02 \pm 0.21$ & & $0.19 \pm 0.18$ & * & $0.21 \pm 0.14$ & * \\
\hline & $1.1-1.2$ & $-0.01 \pm 0.27$ & & $0.17 \pm 0.16$ & * & $0.24 \pm 0.14$ & * \\
\hline & $1.2-1.3$ & $0.04 \pm 0.20$ & & $0.13 \pm 0.15$ & * & $0.23 \pm 0.16$ & * \\
\hline & $1.3-1.4$ & $0.06 \pm 0.15$ & & $0.13 \pm 0.07$ & * & $0.17 \pm 0.09$ & * \\
\hline & $1.4-1.5$ & $0.10 \pm 0.10$ & \multirow[t]{2}{*}{ * } & $0.12 \pm 0.09$ & * & $0.16 \pm 0.09$ & * \\
\hline & $1.5-1.6$ & $0.04 \pm 0.10$ & & $0.09 \pm 0.12$ & * & $0.11 \pm 0.10$ & * \\
\hline & $1.6-1.7$ & $0.07 \pm 0.10$ & \multirow[t]{2}{*}{ * } & $0.06 \pm 0.12$ & & $0.14 \pm 0.08$ & * \\
\hline & $1.7-1.8$ & $0.06 \pm 0.12$ & & $0.11 \pm 0.16$ & * & $0.16 \pm 0.10$ & * \\
\hline & $1.8-1.9$ & $0.11 \pm 0.13$ & \multirow[t]{4}{*}{ * } & $0.10 \pm 0.11$ & * & $0.14 \pm 0.11$ & * \\
\hline & $1.9-2.0$ & $0.05 \pm 0.23$ & & $0.08 \pm 0.20$ & & $0.15 \pm 0.16$ & * \\
\hline & $2.0-2.1$ & $0.09 \pm 0.21$ & & $0.03 \pm 0.24$ & & $0.12 \pm 0.22$ & * \\
\hline & $2.1-2.2$ & $0.01 \pm 0.16$ & & $0.07 \pm 0.21$ & & $0.12 \pm 0.16$ & * \\
\hline
\end{tabular}




\subsubsection{Shoot Trimming Intensity}

The trimming treatments caused large reductions in vine height (Table 6). The OBIA algorithm detected significant changes caused by the Au-1-LIST treatment in the volume, height, area, maximum width, and for the width at the height intervals above the height where the shoots were trimmed (from 1.4 to $2.2 \mathrm{~m}$ ). The trimming treatment of higher intensity (Au-1-HIST) led to a similar trend in the dimension changes, although the change in volume and height were higher, and the differences in width appeared at lower heights than in Au-1-LIST because the trimming of the shoots was done at a lower height.

Table 6. Mean and standard deviation of vine dimension changes after low and high intensity shoot trimming experiment at Ausejo-1. The table is divided in two parts: (1) changes in main dimensions of the vine, (2) changes in the width at different height intervals. Values followed by an asterisk are indicative of significant differences among the vine dimensions before and after the canopy management (paired $T$-test at $p=0.05$ ).

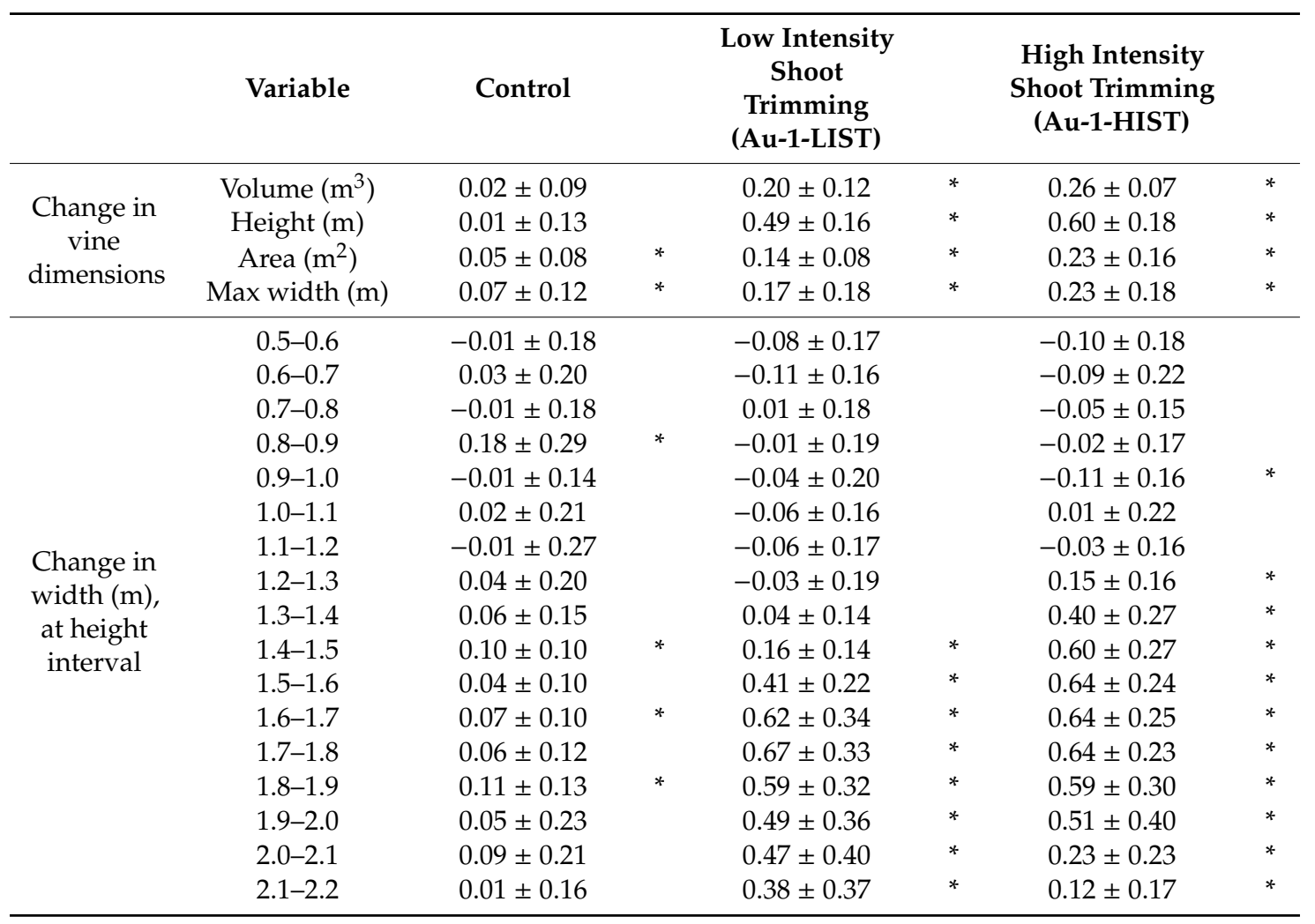

\subsection{Vine Dimensions after the Experiments}

In this section, the results of the analysis of flight after the treatments are considered to study the vine dimensions after the treatments, and to assess whether it is possible to detect the execution of the canopy management operations without the necessity of comparing with a previous flight. Comparisons are presented for the main vine dimensions (volume, height, area, and maximum width) (Table 7), and graphical width profiles in height are also displayed. 
Table 7. Mean and standard deviation of vine dimensions after the canopy management operations. For each experiment and vine dimension, values followed by different letter are statistically different at $p=0.05$ by a Student's T-test.

\begin{tabular}{|c|c|c|c|c|c|}
\hline Experiment & Treatment & Volume $\left(\mathrm{m}^{3}\right)$ & $\begin{array}{l}\text { Maximum } \\
\text { Height (m) }\end{array}$ & Area $\left(m^{2}\right)$ & $\begin{array}{l}\text { Maximum } \\
\text { Width (m) }\end{array}$ \\
\hline \multirow{2}{*}{$\begin{array}{l}\text { Shoot Thinning } \\
\text { (Azagra) }\end{array}$} & Control & $0.21 \pm 0.03 \mathrm{~A}$ & $1.17 \pm 0.08 \mathrm{~A}$ & $0.44 \pm 0.05 \mathrm{~A}$ & $0.61 \pm 0.07 \mathrm{~A}$ \\
\hline & Th & $0.16 \pm 0.04 \mathrm{~B}$ & $1.15 \pm 0.07 \mathrm{~A}$ & $0.35 \pm 0.06 \mathrm{~B}$ & $0.55 \pm 0.06 \mathrm{~B}$ \\
\hline \multirow{3}{*}{$\begin{array}{l}\text { Leaf Removal } \\
\text { Mode } \\
\text { (Traibuenas) }\end{array}$} & Control & $0.45 \pm 0.12 \mathrm{~A}$ & $1.74 \pm 0.11 \mathrm{~A}$ & $0.70 \pm 0.12 \mathrm{~A}$ & $0.86 \pm 0.12 \mathrm{~A}$ \\
\hline & LR-1S & $0.41 \pm 0.13 \mathrm{~B}$ & $1.73 \pm 0.10 \mathrm{~A}$ & $0.68 \pm 0.15 \mathrm{~A}$ & $0.87 \pm 0.14 \mathrm{~A}$ \\
\hline & LR-2S & $0.41 \pm 0.10 \mathrm{~B}$ & $1.75 \pm 0.13 \mathrm{~A}$ & $0.71 \pm 0.13 \mathrm{~A}$ & $0.89 \pm 0.14 \mathrm{~A}$ \\
\hline \multirow{3}{*}{$\begin{array}{l}\text { Leaf Removal } \\
\text { Intensity } \\
\text { (Ausejo-1) }\end{array}$} & Control & $0.52 \pm 0.12 \mathrm{AB}$ & $2.03 \pm 0.16 \mathrm{~A}$ & $0.68 \pm 0.14 \mathrm{~A}$ & $0.90 \pm 0.20 \mathrm{~A}$ \\
\hline & LR-LI & $0.53 \pm 0.07 \mathrm{~A}$ & $2.07 \pm 0.14 \mathrm{~A}$ & $0.63 \pm 0.06 \mathrm{AB}$ & $0.80 \pm 0.05 \mathrm{AB}$ \\
\hline & LR-HI & $0.46 \pm 0.05 \mathrm{~B}$ & $2.03 \pm 0.16 \mathrm{~A}$ & $0.55 \pm 0.07 \mathrm{~B}$ & $0.72 \pm 0.10 \mathrm{~B}$ \\
\hline \multirow{2}{*}{$\begin{array}{c}\text { Shoot Trimming } \\
\text { Detection } \\
\text { (Ausejo-2) }\end{array}$} & Control & $0.65 \pm 0.11 \mathrm{~A}$ & $2.06 \pm 0.15 \mathrm{~A}$ & $0.72 \pm 0.10 \mathrm{~A}$ & $0.92 \pm 0.15 \mathrm{~A}$ \\
\hline & $\mathrm{ST}$ & $0.33 \pm 0.05 \mathrm{~B}$ & $1.42 \pm 0.11 \mathrm{~B}$ & $0.59 \pm 0.08 \mathrm{~B}$ & $0.74 \pm 0.09 \mathrm{~B}$ \\
\hline \multirow{3}{*}{$\begin{array}{l}\text { Shoot Trimming } \\
\text { Intensity } \\
\text { (Ausejo-1) }\end{array}$} & Control & $0.52 \pm 0.12 \mathrm{~A}$ & $2.03 \pm 0.16 \mathrm{~A}$ & $0.68 \pm 0.14 \mathrm{~A}$ & $0.90 \pm 0.20 \mathrm{~A}$ \\
\hline & ST-LI & $0.36 \pm 0.08 \mathrm{~B}$ & $1.62 \pm 0.17 \mathrm{~B}$ & $0.59 \pm 0.12 \mathrm{~B}$ & $0.73 \pm 0.16 \mathrm{~B}$ \\
\hline & ST-HI & $0.26 \pm 0.06 \mathrm{C}$ & $1.44 \pm 0.19 \mathrm{C}$ & $0.54 \pm 0.06 \mathrm{~B}$ & $0.71 \pm 0.11 B$ \\
\hline
\end{tabular}

\subsubsection{Shoot Thinning}

The analysis of the point clouds after the canopy management operations at Azagra field showed that the vines under the STh treatment had significantly lower volume, area, and maximum width than the control vines (Table 7). Despite these significant differences, it was not possible to establish a threshold between treated and un-treated vines, due to the existence of some overlap in the standard deviation among the vine dimensions for both treatments. The shoot thinning, as shown in the width profiles in Figure 7, also significantly reduced the width at the intervals below $1 \mathrm{~m}$ height.

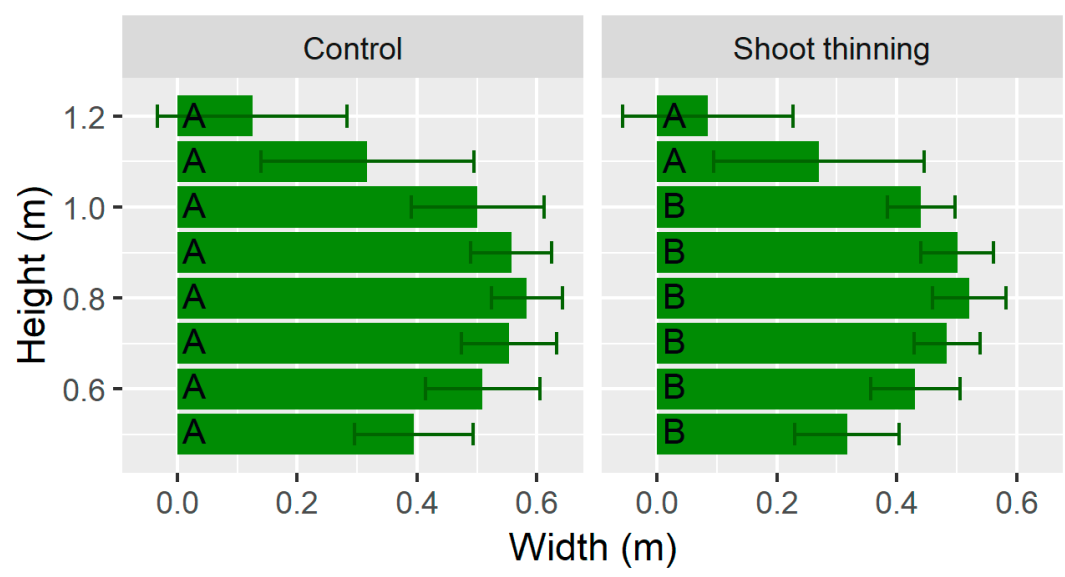

Figure 7. Vine width at different heights after the shoot thinning experiment at Azagra (error bars represent the standard deviation). For each height, different letters indicate significant differences among treatments at $p=0.05$ by a Student's $T$-test. 


\subsubsection{Leaf Removal}

- Leaf removal mode

Removing leaves whether from one or from both canopy sides at the Traibuenas vineyard decreased the volume of leaves in the treated vines compared to the control (Table 7), although they did not result in significant differences regarding the height, area, nor maximum width. However, studying the width profiles (Figure 8), the width at the height intervals below $1 \mathrm{~m}$ was affected by the leaf removal treatments. The removal of leaves at both sides of the vine led to the lowest widths at $0.9-1.0$ and $0.8-0.9$ intervals, while the widest ones were the control vines, and the Tr-TS vines had intermediate values. However, due to the overlap among width values, it was not possible to determine a fixed threshold for accurately detecting the canopy management using only one flight after the operations.

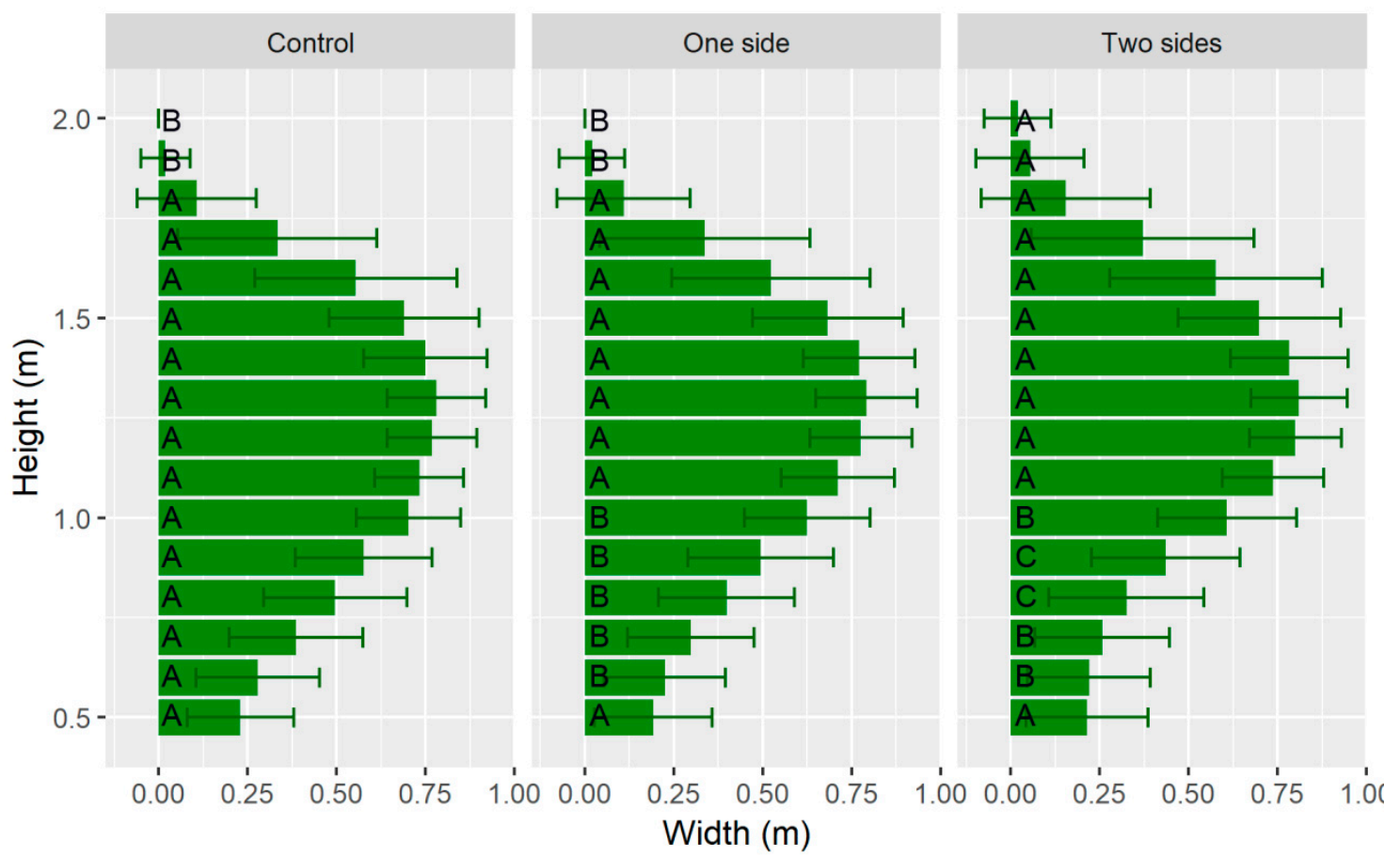

Figure 8. Vine width at different heights after the leaf removal experiment at Traibuenas (error bars represent the standard deviation). For each height, different letters indicate significant differences among treatments at $p=0.05$ by a Student's $T$-test.

- Leaf removal intensity

Regarding leaf removal intensity experiments in Ausejo, there were no significant differences between the control, and LR-LI and LR-HI treatments for the volume and maximum height vine dimensions (Table 7). Increasing the intensity in the leaf removal did cause a significant reduction in the area and maximum width in comparison with the control vines. There also was a reduction in the volume although non-significant compared to the control.

Although the analysis of the main vine dimensions did not detect differences between the LR-LI treatment and the control, the study of the width profile of the vines allowed discriminating the LR-HI treatment (Figure 9), since significant differences were found for the width at height intervals between 1.0 and $1.2 \mathrm{~m}$. Only the LR-LI treatment was significantly narrower than the control treatment at $1.1 \mathrm{~m}$. 

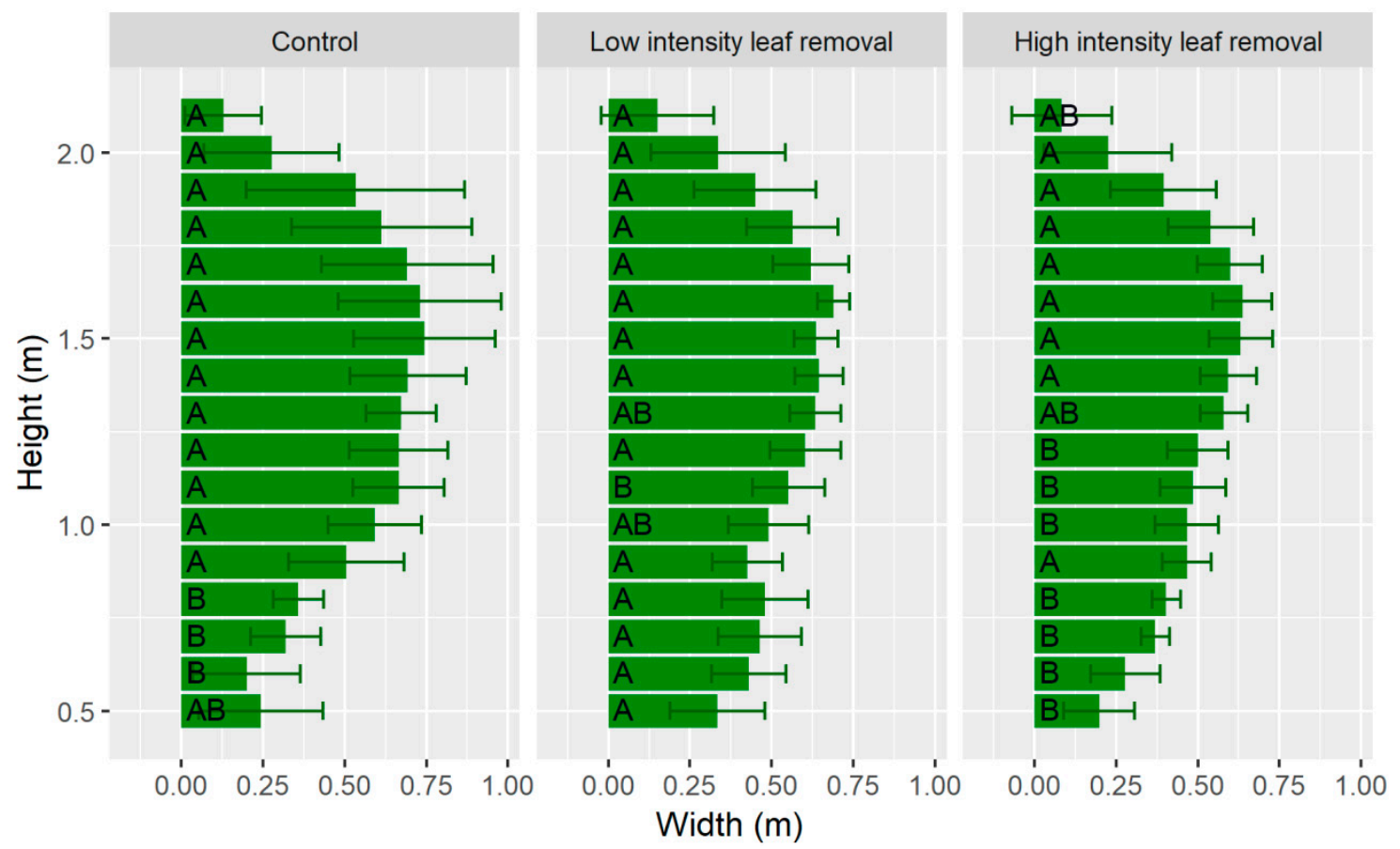

Figure 9. Vine width at different heights after the second leaf removal and trimming experiment at Ausejo-1 vineyard (error bars represent the standard deviation). For each height, different letters indicate significant differences among treatments at $p=0.05$ by a Student's $T$-test.

\subsubsection{Shoot Trimming}

- Shoot trimming detection

Vines at Ausejo-2 vineyard after shoot trimming had significantly lower volume, height, area, and maximum width than the control vines (Table 7). The difference in height was so large that it allowed establishing a threshold for detecting the shoot trimming using data from only one flight after treatment. For example, using $1.75 \mathrm{~m}$ as threshold, $98.75 \%$ of the trimmed vineyards were correctly classified (i.e., 158 vines out of 160 ), and $98.44 \%$ of the no trimmed vineyards were correctly detected (i.e., 315 vines out of 320 ).

The width at different height intervals also depicted the differences between treatments (Figure 10). The most conspicuous differences were detected at higher heights due to the trimming of the shoots.

- Shoot trimming intensity

Both trimming intensities (ST-LI and ST-HI) caused significant differences for the four vine dimensions in regards to the control treatment (Table 7). The differences for the trimming treatments were larger for the maximum height (1.62 $\mathrm{m}$ for ST-LI and $1.44 \mathrm{~m}$ for ST-HI compared to the $2.03 \mathrm{~m}$ height obtained for the control). According to the standard deviation, all the non-trimmed vines had a height above $1.75 \mathrm{~m}$, a value that could be used as height threshold for detecting the correct execution of the trimming treatments considering solely the flight after the canopy management. This threshold classified correctly the $83.33 \%$ of the ST-LI vines, and the $91.67 \%$ of ST-HI vines.

The width profiles for the shoot trimming treatments reflected them through significantly lower width values at the higher height intervals (Figure 11). The higher intensity of the ST-HI treatment led to the reduction in width in a larger interval than for the ST-LI treatment. That is, while this reduction was detected from $1.5 \mathrm{~m}$ height in the lower intensity treatment, it could be detected from $1.3 \mathrm{~m}$ for the higher intensity treatment. 


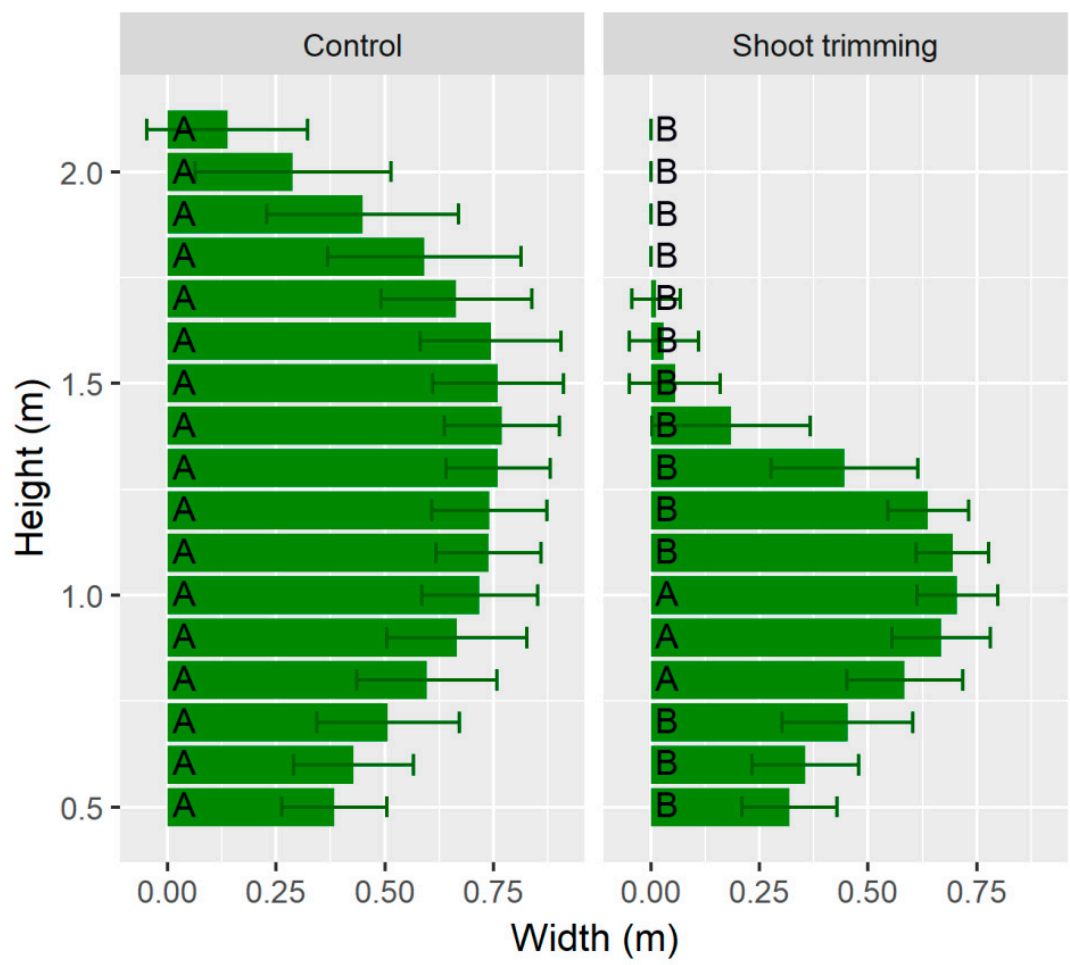

Figure 10. Vine width at different heights after the shoot trimming experiment at the Ausejo-2 vineyard (error bars represent the standard deviation). For each height, different letters indicate significant differences among treatments at $p=0.05$ by a Student's $T$-test.

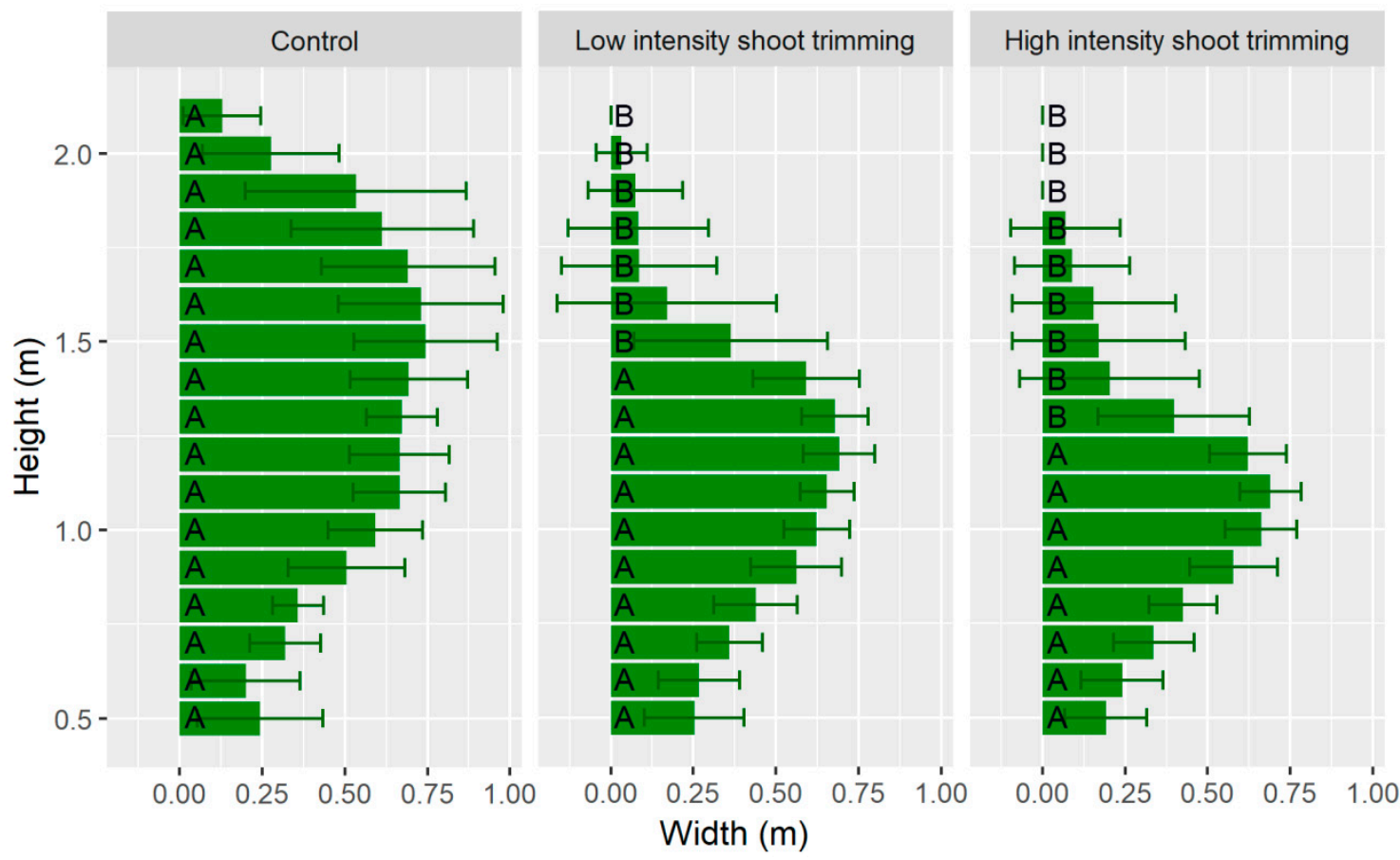

Figure 11. Vine width at different heights after the shoot trimming experiment at the Ausejo-1 vineyard (error bars represent the standard deviation). For each height, different letters indicate significant differences among treatments at $p=0.05$ by a Student's $T$-test. 


\section{Discussion}

The results show that the detection of canopy management operation using data from UAV photogrammetry can be accomplished. The possibilities provided by this approach for farmers can be of great interest since they can reduce the intensity of field inspections to determine if canopy management operations are being performed in due time and manner. The cost-effectiveness of this solution could, at this moment, be questioned, but the expected increase for non-supervised UAV operation and image processing will make these solutions readily usable and affordable for growers.

Regarding the two approaches in the analysis of the UAV-derived data, the first one was successful, that is, the execution of the canopy management operations can be validated through the comparison of the OBIA-measured vine dimensions before and after the treatments. Significant differences in vine dimensions were detected in all the treatments, and these differences matched the characteristics of the treatments. This fact is especially relevant in the case of the shoot thinning, since this treatment is carried out when the shoots are small, and the changes caused to the vine by removing them are subtle and, consequently, hard to detect. Pádua et al. [16] were not able to detect changes in the vineyard volume after a shoot thinning treatment; probably due to the poorer resolution of their data, acquired by flying at a higher altitude $(60 \mathrm{~m})$ and with a lower resolution sensor. This highlights the relevance of choosing an adequate UAV flight plan and sensor in order to achieve the objectives desired.

Leaf removal and shoot thinning led to reductions in the volume, area, and maximum width of the vines. However, what is of more relevance, is that the analysis of the width changes at different height intervals showed that the largest decreases were associated with the heights where the leaves were removed (around $1 \mathrm{~m}$ from the soil). Regarding shoot trimming, changes were associated with decreases in volume, height, area, and maximum width. As opposed to the leaf removal treatments, the biggest reductions in vine width were detected at the upper parts of the vines, where the shoots were trimmed.

Additionally, some unexpected significant differences were detected, such as the reduction in height reported for LR-HI. These differences could be associated with some errors inherent to the point cloud generation, or with real changes in vine dimensions. For example, it is likely the transit of operators among the vine rows and their activity during leaf removal could have caused some shoots to change position or to be damaged before the second flight was made. Apart from those, some other remarkable and unexpected dimension changes were detected in control vines, particularly in the Traibuenas vineyard. These differences are probably associated to changes in both leaf turgor and leaf blade angle associated to water deficit and high atmospheric evaporative demand at mid-day. In this field, the first flight was performed at 9:15 solar time, whereas the second one was done at 11:30, when temperatures were particularly high $\left(34.9^{\circ} \mathrm{C}\right)$. Changes in leaf turgor and angle have been previously reported in grapevine as a response to water deficit and high temperature stress [42], the former being a direct consequence of water deficit, and the latter an adaptation of plants to minimize sunlight interception at noon.

The analysis of the vine dimensions extracted from the point cloud created after the canopy management operations detected significant differences among the treatments in all the experiments. These differences matched the characteristics of the treatments, as also happened in the analysis of the changes in vine dimensions. Shoot thinning influenced the volume, area, and width of the vines; however, it did not cause differences in height nor in the width at the higher height intervals in comparison with the control vines, as the shoots removed were not the longest ones.

In regards to shoot trimming, it caused a large reduction in height, volume, and the width at the highest height intervals, which was linked to the removal of the upper part of the shoots. On the other hand, leaf removal mainly affected the width of the vine, which also modified the area and volume of the vines. In the leaf removal experiment at Ausejo, the vines subjected to high intensity leaf removal (LR-HI) showed lower volume and area than those subjected to low intensity leaf removal (LR-LI). However, there were no significant differences in the main dimensions between LR-LI and control (C) vines. In this case, only the analysis of the width at different height intervals 
made possible the detection of the differences between these treatments. The importance of the width profile analysis in height is also revealed by the experiment carried out at Traibuenas. At that location, both intensities of the leaf removal showed no significant differences between them for the main vine dimensions, although they displayed differences in the width at the height intervals between 0.8 and $1 \mathrm{~m}$. This fact highlights the importance of the analysis of the vine width profile, which has, to the best of our knowledge, been applied for the first time in this work for the analysis of vineyards using photogrammetric point clouds. Escolà et al. [22] reported similar width profiles, but they were created using data from a mobile terrestrial LIDAR scanner, which is less efficient.

In the case of shoot trimming, differences between treatments were very clearly detected. Thus, there were significant differences between the three types of vines considered: control (C), low intensity (ST-LI), and high intensity (ST-HI) trimming.

The second approach in the analysis of the UAV-derived data, i.e., the use of the information provided only by the flight after the treatments, was effective for shoot trimming monitoring. There were significant differences among the vine dimensions after the treatments in all the experiments, and for trimmed plants, it was possible to discriminate trimmed vines on the basis of a fixed threshold. For the rest of the operations (shoot thinning and leaf removal), the overlap among the standard deviation values for the vine dimensions did not allow such a discrimination. When that degree of detection would be required, flight configuration at lower altitude, or the use of higher resolution cameras, could be explored as an alternative. Flying at lower altitudes would require to capture higher amount of images per ha, and more time to cover the same area and to mosaic the imagery $[43,44]$. As a consequence, potential UAV energy restrictions may be a limiting factor for a practical use of the technology and methodology herein presented. Therefore, future research lines could explore the use of higher resolution cameras for trying to detect shoot thinning and leaf removal using only one flight after the management operations.

The data extracted from the vineyard point clouds by the OBIA algorithm have demonstrated their ability to characterize the vine dimensions and to detect the changes that the canopy management operations cause. Therefore, this ability to measure vine dimensions would allow the supervision or inspection of vineyard fields. The degree of detail obtained with the OBIA algorithm opens the door to other applications of using vine dimensions. For instance, knowing vine dimensions in detail could be used to design site-specific treatments adapted to the needs of the crop according size, implying a better use of phytochemicals. According to Campos et al. [45], the combination of information extracted from UAV flights and a decision support system resulted in a $45 \%$ reduction of pesticide foliar application in vineyards. The 3D modelling of vineyards is also useful for the evaluation of vine-rows features (such as inter-row spacing or row orientation) [17] and for the detection of missing plants [46]. In addition, the estimation of vine dimensions throughout a season would allow the generation of dynamic growth maps, and the identification of areas were canopy management operations could be beneficial or needed to be re-designed [16]. Last, a good characterization of canopy management operations in vineyard volume can be an accurate tool to estimate the available residual biomass [47], that can be used as a source of energy $[48,49]$, or as input for the production of adsorbents in water purification processes $[50,51]$.

\section{Conclusions}

This study demonstrates that the use of UAV photogrammetry in combination with an automatic algorithm allows the detection of canopy management operations in vineyards. The use of the proposed methodology would allow supervising the execution of these tasks in an efficient way, substituting the time-consuming field inspections that are used nowadays. To the best of our knowledge, this is the first time that a set of canopy management operations in agricultural fields have been evaluated through the use of photogrammetric point clouds, and it also is the first time that width profiles at different heights have been extracted from photogrammetric point clouds representing a woody crop. 
The results showed that the comparison of the vine dimensions after and before the treatments allowed the detection of all the canopy management operations, since changes in vine dimensions appeared in the parts of the vine where the treatments had been applied. Furthermore, significant differences in the vine structure for the different treatments were detected in all the experiments using only the data from the flight after the management operations, and for trimming it was possible to establish a fixed threshold to detect trimmed vines considering only the data generated from the flight after the treatment. Future research will be focused on the detection of all the canopy management operations using only one flight after their execution.

Author Contributions: Conceptualization, F.L.-G. and L.G.S.; UAV flights and UAV data analysis, F.L.-G., J.T.-S., F.M.J.-B., and A.I.d.C.; field data acquisition and analysis, L.G.S., O.O., D.M., and M.L.; writing-original draft preparation, F.L.-G. and J.T.-S.; writing-review and editing, F.L.-G. and L.G.S.; project administration and funding acquisition, F.L.-G. and L.G.S. All authors have read and agreed to the published version of the manuscript.

Funding: This research was partly financed by the AGL2017-83325-C4-4-R (Spanish Ministry of Science and Innovation AEI/EU-FEDER funds), DECIVID and VINO ROSADO (funds from the Government of Navarra, grant nos. 0011-1365-2017-000113 and 0011-1365-2019-000111), and Intramural-CSIC (grant nos. 201840 E002 and 202040E230) projects. Research of Dr. de Castro was supported by the Juan de la Cierva-Incorporación Program. Diana Marin is beneficiary of a postgraduate scholarships funded by the Universidad Pública de Navarra (FPI-UPNA-2016), and Oihane Oneka of a Youth Guarantee grant for R+D (Ministry of Science and Universities, 17/5/2018). We acknowledge the support of the publication fee by the CSIC Open Access Publication Support Initiative through its Unit of Information Resources for Research (URICI).

Acknowledgments: The authors would like to thank all the staff in B. Coop San Gregorio, Bodegas Ochoa, and Viñedos Barón de Ley for their cooperation with the set-up and maintenance of the experiment.

Conflicts of Interest: The authors declare no conflict of interest.

\section{References}

1. Martínez de Toda, F.; Sancha, J.C.; Zheng, W.; Balda, P. Leaf area reduction by trimming, a growing technique to restore the anthocyanins: Sugars ratio decoupled by the warming climate. Vitis. J. Grapevine Res. 2014, 53, 189-192.

2. Palliotti, A.; Tombesi, S.; Silvestroni, O.; Lanari, V.; Gatti, M.; Poni, S. Changes in vineyard establishment and canopy management urged by earlier climate-related grape ripening: A review. Sci. Hortic. 2014, 178, $43-54$. [CrossRef]

3. Santesteban, L.G.; Miranda, C.; Urrestarazu, J.; Loidi, M.; Royo, J.B. Severe trimming and enhanced competition of laterals as a tool to delay ripening in Tempranillo vineyards under semiarid conditions. Oeno One 2017, 51, 191-203. [CrossRef]

4. León, L.; Díaz-Varela, R.A.; Zarco-Tejada, P.J.; de la Rosa, R. Tree crown parameters assessment using 3D photo reconstruction as a tool for selection in olive breeding programs. ACTA Hortic. 2017, 1-4. [CrossRef]

5. Torres-Sánchez, J.; de Castro, A.I.; Peña, J.M.; Jiménez-Brenes, F.M.; Arquero, O.; Lovera, M.; López-Granados, F. Mapping the 3D structure of almond trees using UAV acquired photogrammetric point clouds and object-based image analysis. Biosyst. Eng. 2018, 176, 172-184. [CrossRef]

6. Colaço, A.F.; Molin, J.P.; Rosell-Polo, J.R.; Escolà, A. Spatial variability in commercial orange groves. Part 1 : Canopy volume and height. Precis. Agric. 2018, 20, 788-804.

7. Jiang, Y.; Li, C.; Takeda, F.; Kramer, E.A.; Ashrafi, H.; Hunter, J. 3D point cloud data to quantitatively characterize size and shape of shrub crops. Hortic. Res. 2019, 6, 43. [CrossRef]

8. $\mathrm{Hu}, \mathrm{K}$; Fu, Z. Research on the Performance of the Ultrasonic Measurement System of the Tree Canopy Volume. Intell. Autom. Soft Comput. 2012, 18, 591-600. [CrossRef]

9. Maghsoudi, H.; Minaei, S.; Ghobadian, B.; Masoudi, H. Ultrasonic sensing of pistachio canopy for low-volume precision spraying. Comput. Electron. Agric. 2015, 112, 149-160. [CrossRef]

10. Andújar, D.; Fernández-Quintanilla, C.; Dorado, J. Matching the best viewing angle in depth cameras for biomass estimation based on poplar seedling geometry. Sensors 2015, 15, 12999-13011. [CrossRef]

11. Hämmerle, M.; Höfle, B. Mobile low-cost 3D camera maize crop height measurements under field conditions. Precis. Agric. 2018, 19, 630-647. [CrossRef]

12. Andújar, D.; Moreno, H.; Bengochea-Guevara, J.M.; de Castro, A.; Ribeiro, A. Aerial imagery or on-ground detection? An economic analysis for vineyard crops. Comput. Electron. Agric. 2019, 157, 351-358. [CrossRef] 
13. Caruso, G.; Tozzini, L.; Rallo, G.; Primicerio, J.; Moriondo, M.; Palai, G.; Gucci, R. Estimating biophysical and geometrical parameters of grapevine canopies ('Sangiovese') by an unmanned aerial vehicle (UAV) and VIS-NIR cameras. Vitis. J. Grapevine Res. 2017, 56, 63-70.

14. de Castro, A.I.; Jiménez-Brenes, F.M.; Torres-Sánchez, J.; Peña, J.M.; Borra-Serrano, I.; López-Granados, F. 3-D characterization of vineyards using a novel UAV imagery-based OBIA procedure for precision viticulture applications. Remote Sens. 2018, 10, 584. [CrossRef]

15. Matese, A.; Gennaro, S.F.D.; Berton, A. Assessment of a canopy height model (CHM) in a vineyard using UAV-based multispectral imaging. Int. J. Remote Sens. 2016, 38, 2150-2160. [CrossRef]

16. Pádua, L.; Marques, P.; Hruška, J.; Adão, T.; Peres, E.; Morais, R.; Sousa, J.J. Multi-temporal vineyard monitoring through UAV-based RGB imagery. Remote Sens. 2018, 10, 1907. [CrossRef]

17. Comba, L.; Biglia, A.; Ricauda Aimonino, D.; Gay, P. Unsupervised detection of vineyards by 3D point-cloud UAV photogrammetry for precision agriculture. Comput. Electron. Agric. 2018, 155, 84-95. [CrossRef]

18. Weiss, M.; Baret, F. Using 3D point clouds derived from UAV RGB imagery to describe vineyard 3D macro-structure. Remote Sens. 2017, 9, 111. [CrossRef]

19. Mesas-Carrascosa, F.-J.; de Castro, A.I.; Torres-Sánchez, J.; Triviño-Tarradas, P.; Jiménez-Brenes, F.M.; García-Ferrer, A.; López-Granados, F. Classification of 3D point clouds using color vegetation indices for precision viticulture and digitizing applications. Remote Sens. 2020, 12, 317. [CrossRef]

20. del-Campo-Sanchez, A.; Ballesteros, R.; Hernandez-Lopez, D.; Ortega, J.F.; Moreno, M.A.; Group, on behalf of A. and C.P.R. Quantifying the effect of Jacobiasca lybica pest on vineyards with UAVs by combining geometric and computer vision techniques. PLOS ONE 2019, 14, e0215521. [CrossRef]

21. Shamshiri, R.; Weltzien, C.; Hameed, I.A.J.; Yule, I.E.; Grift, T.; Balasundram, S.K.; Pitonakova, L.; Ahmad, D.; Chowdhary, G. Research and development in agricultural robotics: A perspective of digital farming. Int. J. Agric. Biol. Eng. 2018, 11, 1-14. [CrossRef]

22. Escolà, A.; Martínez-Casasnovas, J.A.; Rufat, J.; Arnó, J.; Arbonés, A.; Sebé, F.; Pascual, M.; Gregorio, E.; Rosell-Polo, J.R. Mobile terrestrial laser scanner applications in precision fruticulture/horticulture and tools to extract information from canopy point clouds. Precis. Agric. 2017, 18, 111-132. [CrossRef]

23. Blaschke, T.; Hay, G.J.; Kelly, M.; Lang, S.; Hofmann, P.; Addink, E.; Queiroz Feitosa, R.; van der Meer, F.; van der Werff, H.; van Coillie, F.; et al. Geographic object-based image analysis-Towards a new paradigm. ISPRS J. Photogramm. Remote Sens. 2014, 87, 180-191. [CrossRef] [PubMed]

24. Johansen, K.; Raharjo, T.; McCabe, M.F. Using multi-spectral UAV imagery to extract tree crop structural properties and assess pruning effects. Remote Sens. 2018, 10, 854. [CrossRef]

25. Jiménez-Brenes, F.M.; López-Granados, F.; de Castro, A.I.; Torres-Sánchez, J.; Serrano, N.; Peña, J.M. Quantifying pruning impacts on olive tree architecture and annual canopy growth by using UAV-based 3D modelling. Plant Methods 2017, 13, 55. [CrossRef]

26. Sohn, G.; Dowman, I. Data fusion of high-resolution satellite imagery and LiDAR data for automatic building extraction. ISPRS J. Photogramm. Remote Sens. 2007, 62, 43-63. [CrossRef]

27. Tomljenovic, I.; Tiede, D.; Blaschke, T. A building extraction approach for Airborne Laser Scanner data utilizing the Object Based Image Analysis paradigm. Int. J. Appl. Earth Obs. Geoinf. 2016, 52, 137-148. [CrossRef]

28. Yu, H.; Cheng, G.; Ge, X. Earthquake-collapsed building extraction from LiDAR and aerophotograph based on OBIA. In Proceedings of the 2nd International Conference on Information Science and Engineering, Hangzhou, China, 3-5 December 2010; pp. 2034-2037.

29. Jakubowski, M.K.; Li, W.; Guo, Q.; Kelly, M. Delineating Individual Trees from Lidar Data: A Comparison of Vector- and Raster-based Segmentation Approaches. Remote Sens. 2013, 5, 4163-4186. [CrossRef]

30. Johansen, K.; Arroyo, L.A.; Armston, J.; Phinn, S.; Witte, C. Mapping riparian condition indicators in a sub-tropical savanna environment from discrete return LiDAR data using object-based image analysis. Ecol. Indic. 2010, 10, 796-807. [CrossRef]

31. Lopatin, J.; Galleguillos, M.; Fassnacht, F.E.; Ceballos, A.; Hernández, J. Using a multistructural object-based LiDAR approach to estimate vascular plant richness in mediterranean forests with complex structure. IEEE Geosci. Remote Sens. Lett. 2015, 12, 1008-1012. [CrossRef]

32. Machala, M.; Zejdová, L. Forest mapping through object-based image analysis of multispectral and LiDAR aerial data. Eur. J. Remote Sens. 2014, 47, 117-131. [CrossRef] 
33. de Castro, A.I.; Rallo, P.; Suárez, M.P.; Torres-Sánchez, J.; Casanova, L.; Jiménez-Brenes, F.M.; Morales-Sillero, A.; Jiménez, M.R.; López-Granados, F. High-throughput system for the early quantification of major architectural traits in olive breeding trials using UAV images and OBIA techniques. Front. Plant Sci. 2019, 10. [CrossRef] [PubMed]

34. Miranda, C.; Santesteban, L.G.; Escalona, J.M.; Herralde, F.D.; Aranda, X.; Nadal, M.; Intrigliolo, D.S.; Castel, J.R.; Royo, J.B.; Medrano, H. Allometric relationships for estimating vegetative and reproductive biomass in grapevine (Vitis vinifera L.). Aust. J. Grape Wine Res. 2017, 23, 441-451. [CrossRef]

35. Phattaralerphong, J.; Sinoquet, H. A method for 3D reconstruction of tree crown volume from photographs: Assessment with 3D-digitized plants. Tree Physiol. 2005, 25, 1229-1242. [CrossRef]

36. Li, J.; Hu, B.; Noland, T.L. Classification of tree species based on structural features derived from high density LiDAR data. Agric. Meteorol. 2013, 171-172, 104-114. [CrossRef]

37. Park, H.; Lim, S.; Trinder, J.C.; Turner, R. Voxel-based volume modelling of individual trees using terrestrial laser scanners. In Proceedings of the 15th Australasian Remote Sensing \& Photogrammetry Conference (ARSPC), Alice Springs, Australia, 13-17 September 2010.

38. Zhang, Z.; Cao, L.; She, G. Estimating forest structural parameters using canopy metrics derived from airborne LiDAR data in subtropical forests. Remote Sens. 2017, 9, 940. [CrossRef]

39. Arnó, J.; Escolà, A.; Vallès, J.M.; Llorens, J.; Sanz, R.; Masip, J.; Palacín, J.; Rosell-Polo, J.R. Leaf area index estimation in vineyards using a ground-based LiDAR scanner. Precis. Agric. 2012, 14, 290-306. [CrossRef]

40. Arnó, J.; Escolà, A.; Rosell-Polo, J.R. Setting the optimal length to be scanned in rows of vines by using mobile terrestrial laser scanners. Precis. Agric. 2017, 18, 145-151. [CrossRef]

41. Wickham, H. ggplot2: Elegant Graphics for Data Analysis; Springer: Berlin, Germany, 2016.

42. Smart, R.E. Aspects of Water Relations of the Grapevine (Vitis Vinifera). Am. J. Enol. Vitic. 1974, 25, 84-91.

43. López-Granados, F.; Torres-Sánchez, J.; Serrano-Pérez, A.; de Castro, A.I.; Mesas-Carrascosa, F.-J.; Peña, J.-M. Early season weed mapping in sunflower using UAV technology: Variability of herbicide treatment maps against weed thresholds. Precis. Agric. 2016, 17, 183-199. [CrossRef]

44. Mesas-Carrascosa, F.-J.; Torres-Sánchez, J.; Clavero-Rumbao, I.; García-Ferrer, A.; Peña, J.-M.; Borra-Serrano, I.; López-Granados, F. Assessing optimal flight parameters for generating accurate multispectral orthomosaicks by UAV to support site-specific crop management. Remote Sens. 2015, 7, 12793-12814. [CrossRef]

45. Campos, J.; Llop, J.; Gallart, M.; García-Ruiz, F.; Gras, A.; Salcedo, R.; Gil, E. Development of canopy vigour maps using UAV for site-specific management during vineyard spraying process. Precis. Agric. 2019, 20, 1136-1156. [CrossRef]

46. Di Gennaro, S.F.; Matese, A. Evaluation of novel precision viticulture tool for canopy biomass estimation and missing plant detection based on 2.5D and 3D approaches using RGB images acquired by UAV platform. Plant Methods 2020, 16, 91. [CrossRef] [PubMed]

47. Velázquez-Martí, B.; Fernández-González, E.; López-Cortés, I.; Salazar-Hernández, D.M. Quantification of the residual biomass obtained from pruning of vineyards in Mediterranean area. Biomass Bioenergy 2011, 35, 3453-3464. [CrossRef]

48. Spinelli, R.; Magagnotti, N.; Nati, C. Harvesting vineyard pruning residues for energy use. Biosyst. Eng. 2010, 105, 316-322. [CrossRef]

49. Spinelli, R.; Nati, C.; Pari, L.; Mescalchin, E.; Magagnotti, N. Production and quality of biomass fuels from mechanized collection and processing of vineyard pruning residues. Appl. Energy 2012, 89, 374-379. [CrossRef]

50. Karaoğlu, M.H.; Zor, Ş.; Uğurlu, M. Biosorption of $\mathrm{Cr}(\mathrm{III})$ from solutions using vineyard pruning waste. Chem. Eng. J. 2010, 159, 98-106. [CrossRef]

51. Vecino, X.; Devesa-Rey, R.; Moldes, A.B.; Cruz, J.M. Formulation of an alginate-vineyard pruning waste composite as a new eco-friendly adsorbent to remove micronutrients from agroindustrial effluents. Chemosphere 2014, 111, 24-31. [CrossRef]

(C) 2020 by the authors. Licensee MDPI, Basel, Switzerland. This article is an open access article distributed under the terms and conditions of the Creative Commons Attribution (CC BY) license (http://creativecommons.org/licenses/by/4.0/). 